NASA/TM-2005-213825

\title{
Aeroacoustic Analysis of Fan Noise Reduction With Increased Bypass Nozzle Area
}

Richard P. Woodward, Christopher E. Hughes, and Gary G. Podboy Glenn Research Center, Cleveland, Ohio 
Since its founding, NASA has been dedicated to the advancement of aeronautics and space science. The NASA Scientific and Technical Information (STI) Program Office plays a key part in helping NASA maintain this important role.

The NASA STI Program Office is operated by Langley Research Center, the Lead Center for NASA's scientific and technical information. The NASA STI Program Office provides access to the NASA STI Database, the largest collection of aeronautical and space science STI in the world. The Program Office is also NASA's institutional mechanism for disseminating the results of its research and development activities. These results are published by NASA in the NASA STI Report Series, which includes the following report types:

- TECHNICAL PUBLICATION. Reports of completed research or a major significant phase of research that present the results of NASA programs and include extensive data or theoretical analysis. Includes compilations of significant scientific and technical data and information deemed to be of continuing reference value. NASA's counterpart of peerreviewed formal professional papers but has less stringent limitations on manuscript length and extent of graphic presentations.

- TECHNICAL MEMORANDUM. Scientific and technical findings that are preliminary or of specialized interest, e.g., quick release reports, working papers, and bibliographies that contain minimal annotation. Does not contain extensive analysis.

- CONTRACTOR REPORT. Scientific and technical findings by NASA-sponsored contractors and grantees.
- CONFERENCE PUBLICATION. Collected papers from scientific and technical conferences, symposia, seminars, or other meetings sponsored or cosponsored by NASA.

- SPECIAL PUBLICATION. Scientific, technical, or historical information from NASA programs, projects, and missions, often concerned with subjects having substantial public interest.

- TECHNICAL TRANSLATION. Englishlanguage translations of foreign scientific and technical material pertinent to NASA's mission.

Specialized services that complement the STI Program Office's diverse offerings include creating custom thesauri, building customized databases, organizing and publishing research results ... even providing videos.

For more information about the NASA STI Program Office, see the following:

- Access the NASA STI Program Home Page at http://www.sti.nasa.gov

- E-mail your question via the Internet to help@sti.nasa.gov

- Fax your question to the NASA Access Help Desk at 301-621-0134

- Telephone the NASA Access Help Desk at 301-621-0390

- Write to:

NASA Access Help Desk

NASA Center for AeroSpace Information 7121 Standard Drive

Hanover, MD 21076 
NASA/TM-2005-213825

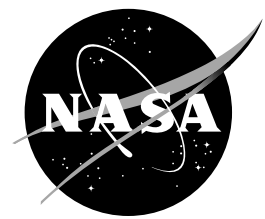

\section{Aeroacoustic Analysis of Fan Noise Reduction With Increased Bypass Nozzle Area}

Richard P. Woodward, Christopher E. Hughes, and Gary G. Podboy Glenn Research Center, Cleveland, Ohio

Prepared for the

11th Aeroacoustics Conference

cosponsored by the American Institute of Aeronautics and Astronautics and the Confederation of European Aerospace Societies

Monterey, California, May 23-25, 2005

National Aeronautics and

Space Administration

Glenn Research Center 
Available from

NASA Center for Aerospace Information 7121 Standard Drive

Hanover, MD 21076
National Technical Information Service 5285 Port Royal Road Springfield, VA 22100

Available electronically at http://gltrs.grc.nasa.gov 


\title{
Aeroacoustic Analysis of Fan Noise Reduction With Increased Bypass Nozzle Area
}

\author{
Richard P. Woodward, Christopher E. Hughes, and Gary G. Podboy \\ National Aeronautics and Space Administration \\ Glenn Research Center \\ Cleveland, Ohio 44135
}

\begin{abstract}
An advanced model turbofan was tested in the NASA Glenn 9-by 15-Foot Low Speed Wind Tunnel (9 by 15 LSWT) to explore far field acoustic effects of increased bypass nozzle area. This fan stage test was part of the NASA Glenn Fan Broadband Source Diagnostic Test, second entry (SDT2) which acquired aeroacoustic results over a range of test conditions. The baseline nozzle was sized to produce maximum stage performance at cruise condition. However, the wind tunnel testing is conducted near sea level condition. Therefore, in order to simulate and obtain performance at other operating conditions, two additional nozzles were designed and tested-one with +5 percent increase in weight flow $(+5.4$ percent increase in nozzle area compared with the baseline nozzle), sized to simulate the performance at the stage design point (takeoff) condition, and the other with a +7.5 percent increase in weight flow $(+10.9$ percent increase in nozzle area) sized for maximum weight flow with a fixed nozzle at sea level condition. Measured acoustic benefits with increased nozzle area were very encouraging, showing overall sound power level (OAPWL) reductions of 2 or more $\mathrm{dB}$ while the stage thrust actually increased by 2 to 3 percent except for the most open nozzle at takeoff rotor speed where stage performance decreased. Effective perceived noise levels for a $1500 \mathrm{ft}$. engine flyover and 3.35 scale factor showed a similar noise reduction of 2 or more EPNdB. Noise reductions, principally in the level of broadband noise, were observed everywhere in the far field. Laser Doppler Velocimetry measurements taken downstream of the rotor showed that the total turbulent velocity decreased with increasing nozzle flow, which may explain the reduced rotor broadband noise levels.
\end{abstract}

\section{Introduction}

An advanced model turbofan was tested in the NASA Glenn 9-by 15-Foot Low Speed Wind Tunnel (9 by 15 LSWT) to explore far field acoustic effects of increased bypass nozzle area. This fan test was part of the NASA Glenn Fan Source Diagnostic Test second entry (SDT2) (refs. 1 to 6 present results from the first entry of the Fan Source Diagnostic Test.) which acquired aeroacoustic results over a range of test conditions. The 9 by 15 LSWT provides a low turbulence, anechoic test environment for fan aeroacoustic tests (refs. 7 through 9). The baseline nozzle was sized for sea level takeoff condition. Two additional nozzles were also tested-with a +5 percent increase in flow, corresponding to a +5.4 percent increase in area (sized for design point (takeoff) condition at 100 percent rotor design speed) and a +7.5 percent increase in flow, corresponding to a +10.9 percent increase in area (sized for maximum flow with a fixed nozzle at sea level condition). Measured acoustic benefits with increased nozzle area were very encouraging, showing overall sound power level (OAPWL) reductions of 2 or more $\mathrm{dB}$ while the stage thrust typically increased by several percentage points. Effective perceived noise levels for a $1500 \mathrm{ft}$. engine flyover and 3.35 scale factor showed a similar noise reduction of 2 or more EPNdB. These noise reduction benefits were primarily for the broadband noise, and were evident throughout the range of measured sideline angles. Concurrent laser Doppler velocimetry measurements taken between the rotor and stator showed a decrease in total turbulent velocity with increased nozzle area, which could help explain the observed reduction in broadband noise with the more open nozzles. This paper builds on the 
results of reference 10 to define fan stage flow characteristics and relate these stage airflow observations with corresponding changes in the far field fan noise.

Earlier fan noise tests reported in the literature have shown the potential for significant reductions in broadband noise levels associated with increased bypass nozzle flow (increased area or reduced throttling). Reference 11 presents results for a $6 \mathrm{ft}$. diameter fan which was tested in the NASA Glenn (formerly NASA Lewis) Quiet Fan Facility. The fan, designated QF-6 had a relatively low 1.2 stage pressure ratio and design rotor tip speed $(750 \mathrm{ft} . / \mathrm{s})$, and represented early 1970's turbofan design. There was no consideration of inflow turbulence control for this test. However, results for QF-6 showed that the far field broadband sound pressure level (SPL) decreased by $4 \mathrm{~dB}$ or more as the stage exit nozzle area increased from 95 to 105 percent of design. The Overall Sound Power Level (OAPWL) showed a similar decrease as the nozzle area was increased. This was accompanied with an increase in the stage adiabatic efficiency with increased nozzle area. This noise reduction with increased bypass nozzle area was repeated for another fan (ref. 12) (QF-2) tested in the NASA Quiet Fan Facility. QF-2 was a 1.5 stage pressure ratio, $1107 \mathrm{ft} . / \mathrm{s}$ tip speed fan which likewise represented 1970 turbofan technology.

References 13 and 14 present forward arc acoustic results for fans statically tested in anechoic facilities using inflow control devices to minimize inlet turbulence. Acoustic results for these two tests also suggested that broadband noise levels may be reduced as the stage flow is increased through reduced downstream throttling (analogous to increased bypass nozzle area). Ginder and Newby (ref. 15) considered forward arc acoustic results for several fans statically tested in an anechoic facility with inflow control as well as the QF-6 results of reference 11. They concluded that the fan stage broadband noise levels were related to changes in the rotor leading edge incidence, which changed with the stage nozzle area, or flow. They concluded that the maximum fan stage broadband noise level changed by about $1.7 \mathrm{~dB}$ per degree change in the rotor incidence angle.

Reductions in turbofan noise levels are an important component of current efforts to reduce overall jet aircraft noise levels. The NASA Glenn Fan Broadband Source Diagnostic Test series provided the opportunity to re-evaluate the potential for fan stage broadband noise reduction for a current technology turbofan. Likewise, the test facility environment enabled taking far-field acoustic data for the entire fan stage (inlet and exhaust) in an anechoic, low turbulence wind tunnel environment simulating takeoff/approach conditions.

\section{Description of Fan Test}

\section{A. Research Hardware}

Results presented herein are for the SDT2 fan stage with the baseline, R4 rotor and baseline radial stator (table 1). The R4 rotor had 22 blades and a nominal 22 inch diameter. The baseline radial stator had 54 blades, thus was cutoff for the fundamental rotor-stator interaction tone (ref. 16). Figure 1 is a photograph of the R4 rotor, and figure 2 is a photograph of the baseline stator. Figure 3 is a cross sectional sketch of the research fan stage with the R4 rotor and baseline stator, and a photograph of the fan and stator without the nacelle installed in the wind tunnel. The rotor-stator spacing is a nominal 2.5 axial rotor chords.

There were three fixed-area fan nozzles designed for testing. Each nozzle was designed to reach a specific operating condition on the rotor and stage operating maps. The fixed-area, "flight-type" engine nozzles are typically sized to maximize engine efficiency cruise conditions at cruise altitude. The three bypass nozzles used for this test were designed as follows: 1) A minimum flow-baseline nozzle, used as the nozzle design for all acoustic testing and designed to achieve minimum stator pressure losses and maximum thrust at take-off conditions without sacrificing cruise operating performance, 2) A design point nozzle, which allowed a +5 percent increase in weight flow with a +5.4 percent increase in nozzle area compared to the baseline nozzle over the fan stage operating range in order to achieve the design point fan weight flow and pressure ratio conditions at 100 percent corrected rotor design speed, and 3) A high flow nozzle, which allowed the maximum weight flow possible through the fan at sea level 
conditions or +7.5 percent above the baseline nozzle with a 10.9 percent increase in nozzle area. The purpose was to determine the effect of reduced rotor blade loading and increased nozzle exit velocity on the fan stage performance and acoustics over a range of operating conditions that would be seen for this particular design in an engine application. Each of the bypass nozzles allowed a different fan stage operating line at sea level conditions. A sketch of the three bypass nozzle geometries is shown in figure 4 .

\section{B. Anechoic Wind Tunnel and Acoustic Instrumentation}

The NASA Glenn 9 by 15 LSWT is located in the low speed return leg of the 8 by 6 Supersonic Wind Tunnel. The tunnel test section walls, floor, and ceiling have acoustic treatment to produce an anechoic test environment. Figure 5 is a sketch of the research fan installed in the 9 by 15 LSWT. Sideline acoustic data were acquired with a computer-controlled translating microphone probe and with three aft microphone assemblies mounted to the tunnel floor. The translating microphone probe acquired data at 48 sideline geometric angles from $27.2^{\circ}$ to $134.6^{\circ}$ relative to the fan rotor plane. The translating probe traverse was 89 inches from the fan rotational axis (about four fan diameters). A wall-mounted microphone probe was placed at a reference location adjacent to the translating probe home position (134.6 $6^{\circ}$, maximum aft travel). The three fixed microphone assemblies were mounted at the home axial position to acquire aft acoustic data at geometric angles of $140^{\circ}, 150^{\circ}$, and $160^{\circ}$. Data were also acquired with an acoustic barrier wall installed adjacent to the fan which effectively blocked aft-radiated fan noise (fig. 6). The acoustic data were acquired through a digital computer system and stored for post-run analysis.

Figure 7 is a photograph of the research fan installed in the 9 by 15 LSWT. Figure 8 shows the fan installation with the acoustic barrier wall in place. Downstream fixed microphones were not used with the wall installed because of acoustic blockage. The sideline traversing microphone probe may be seen to the left of the fan in both photographs.

\section{Results and Discussion}

\section{A. Aerodynamic Performance}

The results indicate that there was an increase in stage thrust with increased bypass nozzle area at most fan speeds. However, aerodynamic data taken concurrently with acoustic testing were limited to rotor and stator assembly thrust and torque due to the need for clean airflow within the model (removal of protruding measuring rakes, etc.). Therefore, the thrust values presented herein are from rotating and static force balance measurements made during acoustic testing. Thrust values are available for the rotor and for the stator/nacelle/afterbody assembly, which includes the stators, flight nacelle, and aft inner bypass flowpath representing the outer boundary of the simulated core hardware downstream of the bypass nozzle. Fan stage thrust measurements are a combination of the rotor thrust from rotating force balance measurements and stator/nacelle/afterbody thrust from static force balance measurements obtained simultaneously during testing. Results from these force balance measurements provided valid rotor and stage thrust values at tunnel test conditions.

Figure 9 shows the increase in corrected weight flow, and figure 10 shows the corrected stage thrust, respectively as a function of the corrected rotor tip speed for the three bypass nozzle designs tested. Figure 9 shows a consistent increase in corrected weight flow with increased nozzle area at all rotor test speeds, except for the high flow nozzle at the highest rotor speeds-100 percent corrected rotor design speed and above. Figure 10 likewise shows a consistent increase in stage thrust with increased nozzle area at all rotor test speeds, except for the high flow nozzle at the highest rotor speeds. The accuracy of the measured thrust is $\pm 10 \mathrm{lbf}$, or \pm 0.25 percent of the full scale measurement range (4000 lbf.) of the combined balances. A description of the technique used for force balance performance measurement can be found in reference 17 . 
Figure 11 shows the percent change in corrected stage thrust for the three nozzle flows. The results of figure 11 were obtained by inspecting the thrust levels at particular rotor tip speeds in figure 9. Stage thrust levels for the +5 percent flow nozzle were about 3 percent higher than for the reference nozzle at approach rotor speed, and slightly more than 2 percent higher at cutback and takeoff rotor speed. Even higher thrust levels are seen for the +7.5 percent flow nozzle at approach and cutback rotor speeds. However, thrust levels for this nozzle area drop off toward takeoff (design) rotor speed-indicating degrading stage flow conditions for this nozzle at high rotor speeds.

Figures 12 and 13 show the measured rotor thrust as a function of corrected rotor tip speed. Unlike the stage thrust, the rotor thrust typically showed a reduction with increasing nozzle area. The rotor thrust levels for the +5 percent flow nozzle were 1 percent less that that for the reference nozzle at approach rotor speed, and 2 percent lower at higher rotor speeds. Rotor thrust levels for the +7.5 percent flow nozzle were significantly lower, showing a 4 percent thrust reduction relative to reference nozzle thrust at approach rotor speed, 6 percent less at cutback sped, and dropping to around 11 percent less at takeoff rotor speed. Figures 12 and 13 demonstrate that the stator thrust is more than compensating for the losses in the rotor, producing an overall increase in stage thrust as the nozzle area is opened.

The thrust results (figs. 10 to 13) suggest that there is lower rotor blade loading associated with increased nozzle area and higher axial flow. The stator, however, appears to have been more effective in generating significantly more thrust with increased nozzle flow. This is likely due to the increase in lift in the thrust component direction because of the higher axial velocity with higher weight flow through the model. The exception is the most open nozzle area ( +7.5 percent flow) at rotor speeds above 87.5 percent, where the thrust results show that both the rotor and stage performance has degraded significantly. This may be due to shock losses over a larger spanwise section of the blade because of the higher axial flow velocity associated with the higher weight flows compared to that for the other two nozzles at the same fan speeds. The flow over the rotor becomes transonic at 87.5 percent design speed. Another possibility is a stronger blade-to-blade passage shock that may also be deeper within the passage, causing a disruption of the flow over the rotor blades resulting in a drop in blade loading.

There was also an increase in the stage adiabatic efficiency (fig. 14) for the +5 percent flow nozzle at all fan speeds and for the +7.5 percent flow nozzle through cutback fan speed. Deteriorating performance for the +7.5 percent flow nozzle is evident in a loss of stage efficiency at fan speeds approaching design.

\section{B. Acoustic Data Reduction}

All of the fan acoustic data were acquired at 0.10 tunnel Mach, which is sufficient to achieve acoustic flight effect (ref. 18). Sideline data are presented in terms of emission angles. The emission angles are related to the geometric or observed angles by the relationship:

$$
\Theta_{\mathrm{em}}=\Theta_{\text {geom }}-\sin ^{-1}\left(\mathrm{M}_{0} \sin \Theta_{\text {geom }}\right)
$$

where $\Theta_{\mathrm{em}}$ and $\Theta_{\text {geom }}$ are, respectively, the emission and observed sideline angles, and $\mathrm{M}_{0}$ is the test section Mach number. The observed angles for the sideline translating microphone probe are then $25^{\circ}$ to $130^{\circ}$, and the three fixed microphones measure aft observed angles of $136^{\circ}, 147^{\circ}$, and $158^{\circ}$. This angular range was sufficient to define the sideline noise profile for this aft-dominated fan for flyover EPNL calculations.

Digital acoustic data were processed as constant bandwidth spectra. Spectra were acquired and averaged at each translating probe or fixed mic position with 5.9 and $59 \mathrm{~Hz}$ bandwidths. These constant bandwidth spectra were electronically merged and used to generate $1 / 3$-octave spectra. Sound power level (PWL) spectra were calculated from the SPL spectra assuming spherical symmetry through the range of sideline data acquisition. Possible noise contributions outside the sideline range were ignored. 


\section{Acoustic Results}

Figure 15 shows the overall sound power level (OAPWL) as a function of stage thrust for the three test nozzle areas. The OAPWL was calculated from the $59 \mathrm{~Hz} \mathrm{BW}$ spectra over a 1 to $50 \mathrm{~K}$ frequency range for sideline emission angles from $25^{\circ}$ to $158^{\circ}$. There is a significant noise decrease associated with increasing nozzle area (and flow)-especially at lower rotor speeds. Figure 16 shows the calculated effective perceived noise level (EPNL) for a $1500 \mathrm{ft}$. "engine flyover" and a 3.35 scale factor. The curves in figure 16 are very similar to those of figure 15, showing that, for this fan stage, acoustic benefits can be evaluated using either overall sound power level or flyover perceived noise level.

Figure 17 shows the change in EPNL for the more open nozzles relative to that for the baseline, sea level design nozzle. These delta EPNL were measured at constant thrust levels interpolated from the curves of figure 16. Increasing the nozzle flow by 5 percent resulted in a 2 EPNdB noise reduction at rotor speeds up to cutback, and around a $1 \mathrm{EPNdB}$ reduction at higher rotor speeds. Further increasing the nozzle flow to +7.5 percent gave noise reductions of about 3 EPNdB relative to the baseline nozzle at lower rotor speeds (near approach), although the noise reduction with the +7.5 percent flow nozzle was significantly higher at the lowest test fan speeds. Noise reductions for the +5 and +7.5 percent flow nozzles were about the same at high subsonic to design rotor speeds.

Figures 18 and 19 show corresponding EPNL with the acoustic barrier wall in place (forward radiating noise). Interestingly, the noise reduction with increased nozzle area (fig. 18) is even greater than what was observed without the barrier wall. The results of figure 18 were interpolated to show the change in noise level relative to the baseline nozzle at a constant stage thrust (fig. 19). Increasing the nozzle flow by +5 percent resulted in about a 2 to $4 \mathrm{EPNdB}$ noise reduction at subsonic tip speeds, and up to $3 \mathrm{~dB}$ at design speed. Increasing the nozzle flow by +7.5 percent gave noise reductions from 3 to $7 \mathrm{EPNdB}$ at subsonic tip speeds and as much as $7.5 \mathrm{~dB}$ at design rotor speed. The forward radiating noise levels near designated cutback (transonic rotor tip speed) were mixed, showing additional noise for the +7.5 percent flow nozzle, and little change with the +5 percent flow nozzle.

The noise reductions associated with increased nozzle flow were primarily broadband noise. Figures 20 through 22 show sound power level spectra at the three fan stage rating conditions. Blade/vane numbers for this fan stage result in the fundamental rotor-stator interaction tone being essentially cut off at lower rotor speeds. Broadband noise levels at 61.7 percent design rotor speed (fig. 20) are up to $3 \mathrm{~dB}$ lower for the +5 percent flow nozzle and $6 \mathrm{~dB}$ lower for the +7.5 percent flow nozzle relative to noise levels for the baseline nozzle. The 2BPF interaction tone (cut-on) shows a small increase with increasing nozzle area. As will be shown with the laser-Doppler velocimeter results, there was an increase in rotor axial velocity and subsequent wake interaction with the stator with higher nozzle flow.

There is a significant increase in BPF tone level with increasing nozzle flow at 87.5 percent rotor speed (fig. 21). Again, increasing the nozzle flow effectively increased the rotor relative velocity and wake strength. This is the speed region where the rotor relative velocity becomes transonic toward the tip, accompanied by the emergence of the "rotor-alone" tones and multiple pure tones (MPT, shaft order tones). The rotor-stator interaction tones (nBPF) are a subset of the multiple pure tones, with their level including a contribution from the MPT noise. Thus small changes in the rotor relative velocity can generate significant changes in the rotor fundamental tone and multiple pure tones as evidenced in the spectra of figure 21. There is a more modest reduction in broadband noise of about $2 \mathrm{~dB}$ with both increased flow nozzles at 87.5 percent fan design speed. The noise "hump" at about $1 / 2$ BPF for the baseline nozzle is unexplained.

The rotor tip relative velocity is well into the sonic range at design fan speed (fig. 22). Consequently the multiple pure tones are well established regardless of nozzle flow changes. The BPF tone level shows a small increase with increasing nozzle flow at design speed with a corresponding small decrease in broadband noise level.

Observed noise reductions with increased nozzle flow typically occurred at all measured sideline angles. Figures 23 through 25 show $59 \mathrm{~Hz}$ bandwidth sound pressure level directivities for the first two rotor tones and representative broadband noise at, respectively 61.7, 87.5, and 100 percent design rotor speed. At 61.7 per speed the noise level at the cutoff BPF frequency (fig. 23(a)) was reduced by about 
$2 \mathrm{~dB}$ with the +5 percent flow nozzle, and about $5 \mathrm{~dB}$ with the +7.5 percent flow nozzle. The $2 \mathrm{BPF}$ tone (fig. 23(b)) showed a noise increase with increased nozzle flow at some sideline angles, in agreement with the corresponding PWL spectra of figure 20. The representative broadband directivities between BPF and 2BPF (fig. 23(c)) again show a nominal $2 \mathrm{~dB}$ reduction with the +5 percent flow nozzle and $5 \mathrm{~dB}$ reduction with the +7.5 percent flow nozzle.

The designated "cutback" rotor speed (87.5 percent design) is at transonic tip speed where rotor-alone noise begins to dominate stage noise. Increased nozzle flow at this rotor speed results in a significant increase in BPF tone level (fig. 24(a)) as much $15 \mathrm{~dB}$ at the $70^{\circ}$ sideline emission angle. Also, this increased noise is not uniform over all sideline angles, but somewhat localized from $40^{\circ}$ to $110^{\circ}$ emission angles. It is possible that the BPF tone (which is just cut on at this rotor speed) is more strongly cut on with higher rotor relative velocities associated with increased nozzle flow. There is a smaller increase in the 2BPF tone (fig. 24(b)) with increased nozzle flow, and essentially no change in broadband level with increased nozzle flow (fig. 24(c)).

The BPF tone level at design rotor speed (fig. 25(a)) shows less change with nozzle flow. The BPF tone is primarily rotor-alone noise at this higher rotor speed. However, there is about a small increase in the 2BPF tone at this rotor speed (fig. 25(b)) with the +7.5 percent flow nozzle. The representative broadband noise levels between BPF and 2BPF is only slightly reduced with increased nozzle flow at design rotor speed (fig. 25(c)).

\section{Laser Doppler Velocimeter Results}

In addition to the aerodynamic and acoustic performance data obtained during this test, flow field velocity measurements were also made using a laser Doppler velocimeter (LDV). The LDV data were obtained in order to determine how the wake flow generated by the rotor changes as the nozzle area changes. These wake data can be used to explain some of the observations made above regarding how the acoustic spectra change as the nozzle area (and flow) is increased.

Figure 26 shows both a schematic of the model as it was configured during the LDV testing and the axial location at which the LDV wake surveys were conducted. Although the far field acoustic data presented above were obtained with the baseline radial stators installed, it was necessary to obtain the LDV data with a set of swept stators since this was the only configuration for which an LDV window was available. As can be seen in figure 26 the LDV data were acquired in an axial plane which intersects the leading edge of the swept stators at the hub. This axial plane also corresponds to the leading edge location of the baseline radial stators that were used during the acoustic testing. Figure 26 also shows that a bellmouth inlet was installed during the LDV testing, not the flight inlet (fig. 3) used during the acoustic testing.

Figures 27 and 28 show how the rotor wake flow varies with changes in nozzle area as measured at the approach and cutback conditions, respectively. Parts (a) and (b) of these figures show that axial velocities increase and tangential velocities decrease in the rotor wake as nozzle area increases. As a result, swirl angle also decreases (shown in part (c)). The decreased swirl suggests that the loading on the rotor blades decreases as nozzle area increases. In general, this decreased blade loading should lead to a decrease in the amount of turbulence generated by each blade. The plots shown in part (d) of each figure show that this was the case-the measured turbulence level in the rotor wake decreased as nozzle area increased. This decreased rotor wake turbulence will result in decreased levels of rotor/stator interaction broadband noise-a result which is evident in the acoustic spectra plots presented in figures 20 and 21. Both of these plots show a reduction in broadband noise with increasing nozzle area.

The broadband acoustic data presented for the take-off condition in figure 22 show a different trend. These data are similar to the approach and cutback condition data in that they show a decrease in the broadband level as the nozzle area is increased from 0 to +5.4 percent open, but they are unlike the other data in that they show an increase in high frequency broadband noise as the nozzle area is increased further to +10.9 percent open. The LDV flow field data can also be used to explain this anomaly. Figure 29 shows the variation in rotor wake flow with increasing nozzle area as measured at the take off condition. Like the data obtained at the two lower speeds, axial velocities increase (part (a)), and both 
tangential velocities (part (b)) and swirl angles (part (c)) decrease as nozzle area increases. The reduced swirl implies that the blade loading decreases with increasing nozzle area-a result that should lead to less turbulence generated by the blades. However, as indicated in part (d) of figure 29, the turbulence generated by the blades actually increases over much of the blade span as the nozzle area increases between +5.4 and +10.9 percent open (flow increase from +5 to +7.5 percent).

Figure 30 provides a more detailed look at the wake flows measured at the take off speed. The total turbulent velocity contours (defined as the square root of the sum of the squares of the standard deviations of the two velocity components measured at each point in space) presented in this figure indicate that the outer portions of the blade wakes get thicker and more turbulent as the nozzle area increases between +5.4 and +10.9 percent. This increased blade wake thickness may be indicating a flow separation on the rotor blades resulting, perhaps, from stronger shocks on the blades or from non-optimum inflow angles. In any event, this increase in blade wake turbulence seems to account for the increase in high frequency broadband noise illustrated in figure 22. These thicker wakes are also consistent with the degraded aerodynamic performance measured at this test condition noted earlier in conjunction with figures 13 and 14.

The trends indicated by the LDV data also suggest an explanation for the increase in BPF and MPT noise which occurs when the nozzle is opened at the cutback speed. Previous reports (refs. 4 and 5) have presented LDV data obtained within the rotor blade passages at a radial location 0.4 inches inboard of the tip during a test in which the baseline nozzle was installed. These data show that normal shocks exist on the suction side of the blades when the fan is operating at the cutback speed. The plot presented in figure 29(a) indicates that axial flow velocities increase as the nozzle area increases from the baseline condition. The increased axial velocities would lead to higher relative flow velocities on the blades which, in turn, would be expected to lead to stronger passage shocks. The increased noise produced by these shocks is evident in the acoustic spectra of figure 22 which show that both the BPF tone and the Multiple Pure Tones increase as the nozzle area increases.

\section{E. Implications for Turbofan Engine Noise Reduction}

Results shown in this report suggest that a variable area bypass exhaust nozzle for a typical turbofan engine may be an effective way to further decrease engine fan stage noise and possibly realize a concurrent thrust increase. The baseline fixed-area fan nozzle in this test was sized for maximum stage performance at sea level condition. Turbofan engine bypass exhaust nozzles are typically sized for maximum performance at the portion of the aircraft flight profile where most of the flight time is spenttypically at the cruise condition. Increasing the nozzle flow within the envelope defined by desirable engine performance reduced the fan stage noise in this scale model test. Thus it may be desirable to employ a variable area engine bypass exhaust nozzle as a technique to reduce fan stage noise levels at all rotor operating speeds. Even the addition of a limited position variable area bypass nozzle, in order to reduce mechanical complexity and weight, might be an effective retrofit to existing turbofan engines to control fan stage noise and realize additional noise reduction without sacrificing aerodynamic performance

\section{References}

1. Woodward, R.P., Hughes, C.E., Jeracki, R.J., and Miller, C.J., "Fan Noise Source Diagnostic TestFar-field Acoustic Results, AIAA-2002-2427, June, 2002.

2. Hughes, C.E., “Aerodynamic Performance of Scale-Model Turbofan Outlet Guide Vanes Designed for Low Noise, "AIAA-2002-0374, January 2002.

3. Hughes, C.E., Jeracki, R.J., and Miller, C.J., "Fan Noise Source Diagnostic Test-Rotor Alone Aerodynamic Performance Results," AIAA-2002-2426, June 2002.

4. Podboy, G.G., Krupar, M.J., Helland, S.M., and Hughes, C.E., "Steady and Unsteady Flow Field Measurements within a NASA 22 Inch Fan Model," AIAA-2002-1033, January 2002. 
5. Podboy, G.G., Krupar, M.J., Hughes, C.E., and Woodward, R.P., "Fan Source Diagnostic Test-LDV Measured Flow Field Results," AIAA-2002-2431, June 2002.

6. Heidelberg, L.J., "Fan Noise Source Diagnostic Test-Tone Model Structure Results," AIAA-2002-2428, June 2002.

7. Dahl, M.D., and Woodward, R.P., "Comparison between Design and Installed Acoustic Characteristics of the NASA Lewis 9-by 15-Foot Low Speed Wind Tunnel Acoustic Treatment," NASA TP-2996, April 1990.

8. Dahl, M.D., and Woodward, R.P., "Background Noise Levels Measured In the NASA Lewis 9-by 15Foot Low Speed Wind Tunnel," NASA TP-3274, November 1992.

9. Woodward, R.P., and Dittmar, J.H., "Background Noise Levels Measured in the NASA Lewis 9-by 15-Foot Low-Speed Wind Tunnel," NASA TM-106817, AIAA-95-0720, January 1995.

10. Woodward, R.P., and Hughes, C.E., "Noise Benefits of Increased Fan Bypass Nozzle Area," AIAA-2005-1201, NASA/TM-2004-213396, January, 2005.

11. Woodward, R.P., Lucas, J.G., and Stakolich, E.G., "Acoustic and Aerodynamic Performance of a 1.83-Meter (6-ft) Diameter 1.2-Pressure-Ratio Fan (QF-6),” NASA TN D-7809, December 1974.

12. Woodward, R.P., Lucas, J.G., and Balombin, J.R., "Acoustic and Aerodynamic Performance of a 1.5-Pressure-ratio, 1.83-Meter (6-ft) Diameter Fan Stage for Turbofan Engines (QF-2)," NASA TM X-3521, April, 1977.

13. Woodward, R.P., and Glaser, F.W., "Effect of Inflow Control on Inlet Noise of a Cut-on Fan," AIAA Journal, vol. 19, no. 3, March, 1981, pp. 387-392.

14. Gliebe, P.R., "The Effect of Throttling on Forward Radiated Fan Noise," AIAA-79-0640, March, 1979.

15. Ginder, R.B. and Newby, D.R., "An Improved Correlation for the Broadband Noise of High-Speed Fans," AIAA Journal of Aircraft, vol. 14, no. 9, September, 1977, pp. 844-849.

16. Tyler, J.M. and Sofrin, T.G., "Axial Flow Compressor Noise Studies," SAE Trans, vol. 70, 1962, pp. 309-332.

17. Jeracki, R.J., "Model Engine Performance Measurement from Force Balance Instrumentation," NASA/TM-1988-208486, AIAA-98-3112, July 1998.

18. Chestnutt, D., "Flight Effects of Fan Noise," NASA CP-2242, January, 1982.

TABLE 1.-SDT2 RESEARCH FAN STAGE DESIGN PARAMETERS

R4 Rotor

\begin{tabular}{|l|c|}
\hline No. of blades & 22 \\
\hline Tip diameter, in. & 22 \\
\hline Inlet radius ratio & 0.30 \\
\hline Corrected design speed, rpm & 12,657 \\
\hline Design tip speed, ft./s & 1,215 \\
\hline Corrected weight flow, lbm/s & 100.5 \\
\hline Specific flow, lbm/s-ft ${ }^{2}$ & 41.8 \\
\hline Stage pressure ratio & 1.47 \\
\hline
\end{tabular}

Baseline Stator

\begin{tabular}{|c|c|c|c|}
\hline No. Vanes & L. E. Sweep & Aspect Ratio & Solidity \\
\hline 54 & $0^{0}$ & 3.51 & 1.52 \\
\hline
\end{tabular}




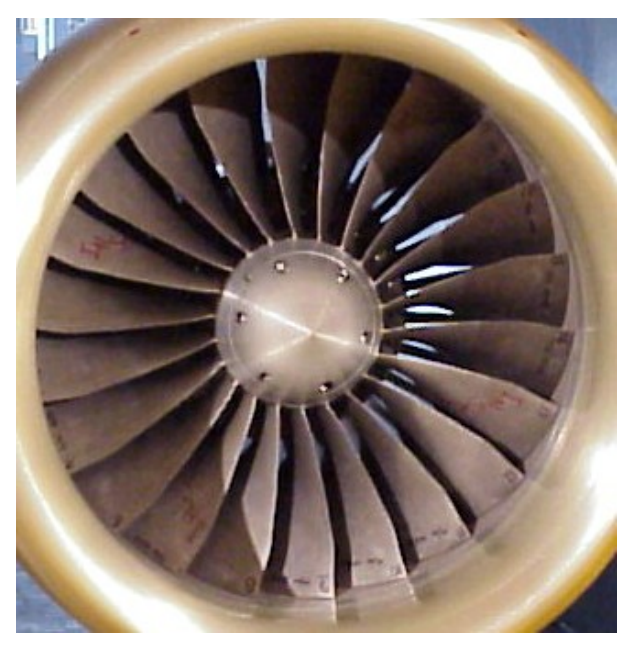

Figure 1.-Photograph of R4 rotor.

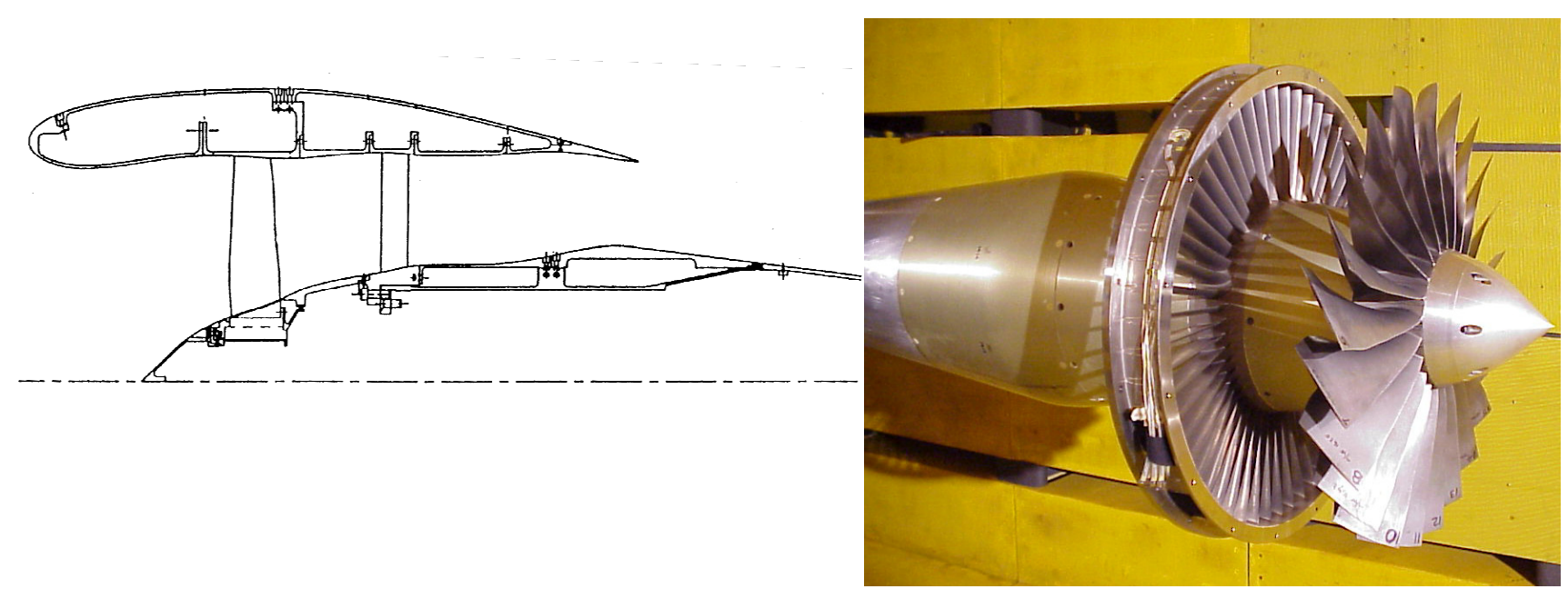

Figure 3.-Cross sectional sketch and photograph of test fan stage with R4 rotor and baseline stator. 


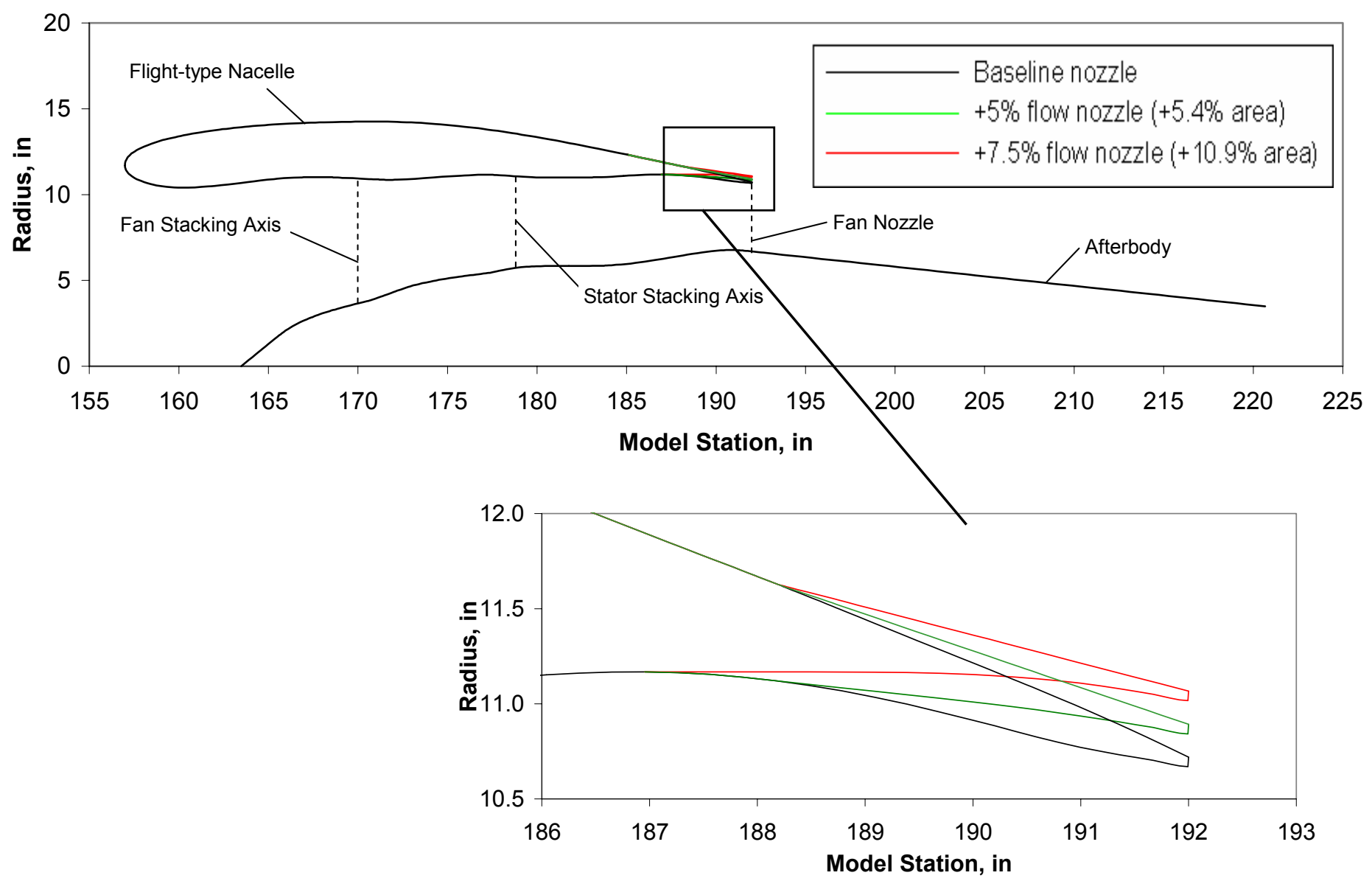

Figure 4.-Sketch of fan nozzle geometry configurations. 


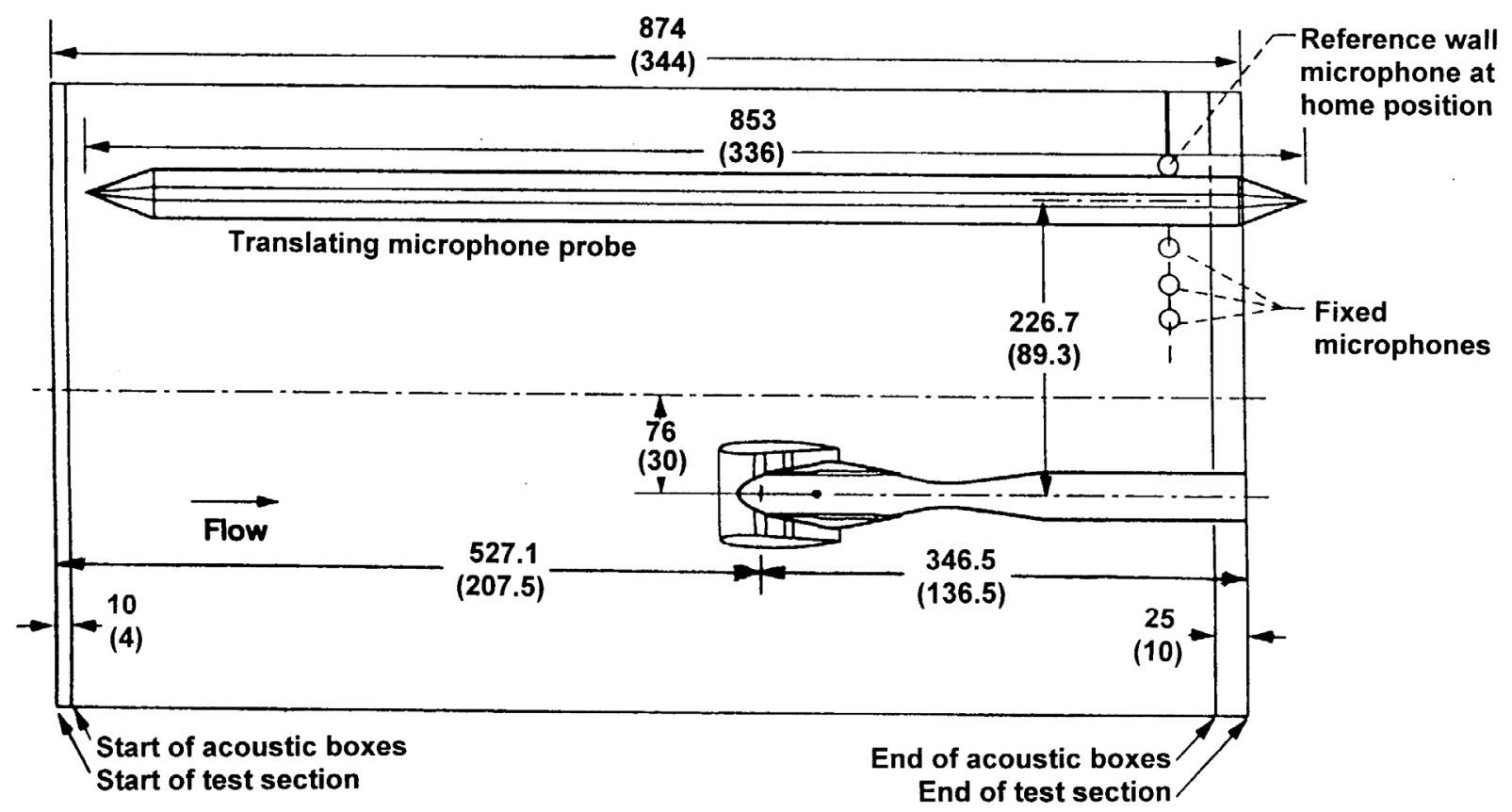

Figure 5.- Sketch of the model fan installed in the 9- by 15-Foot Low Speed Wind Tunnel. Far-field acoustic data were acquired with a translating microphone probe and aft fixed microphones. (Dimensions in $\mathrm{cm}$ (in.)).
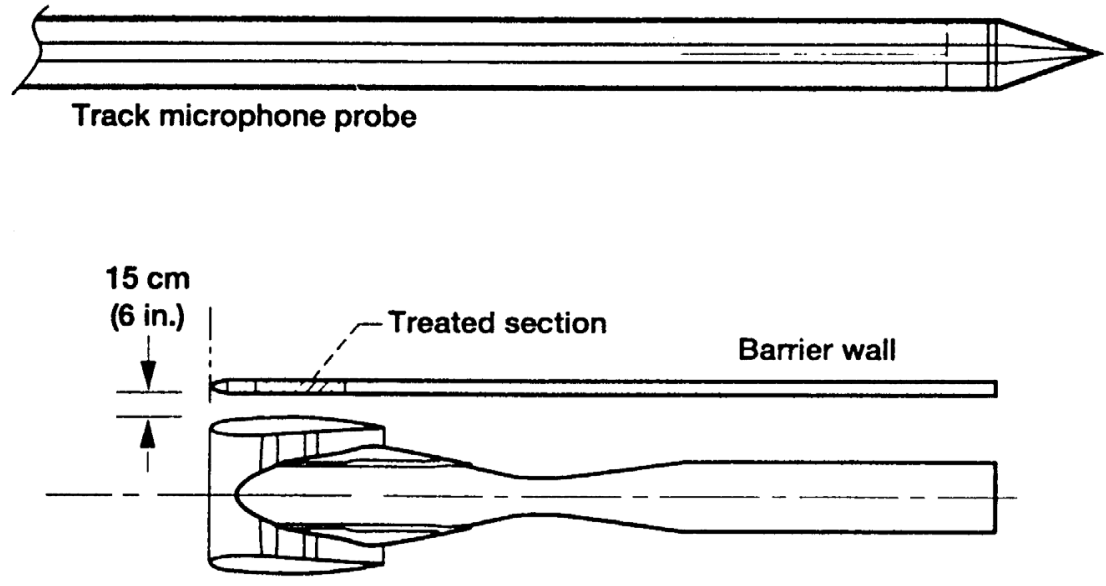

Figure 6.-Sketch showing location of acoustic barrier wall relative to model fan. (Dimensions in $\mathrm{cm}$ (in)). 

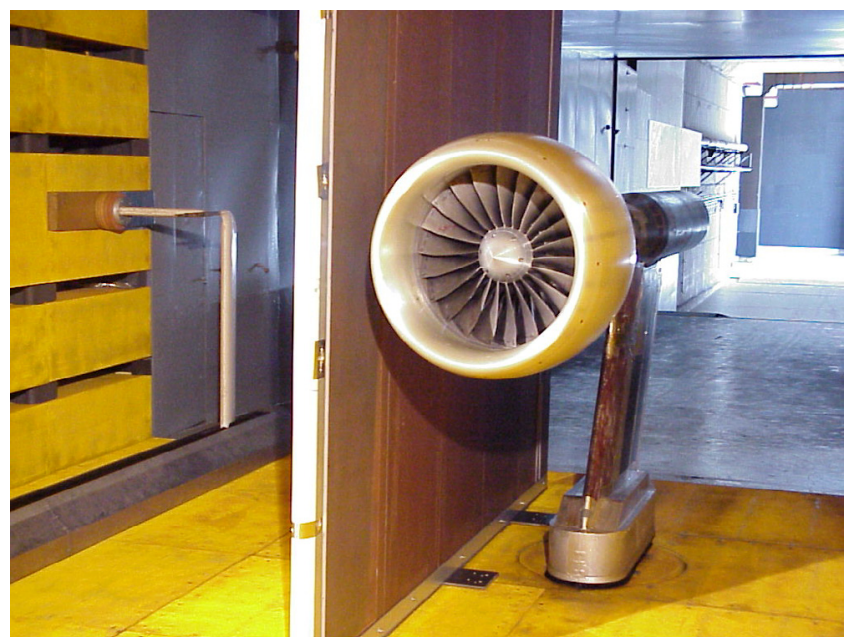

Figure 7.-Photograph of the research fan installed in the 9 by 15 LSWT.

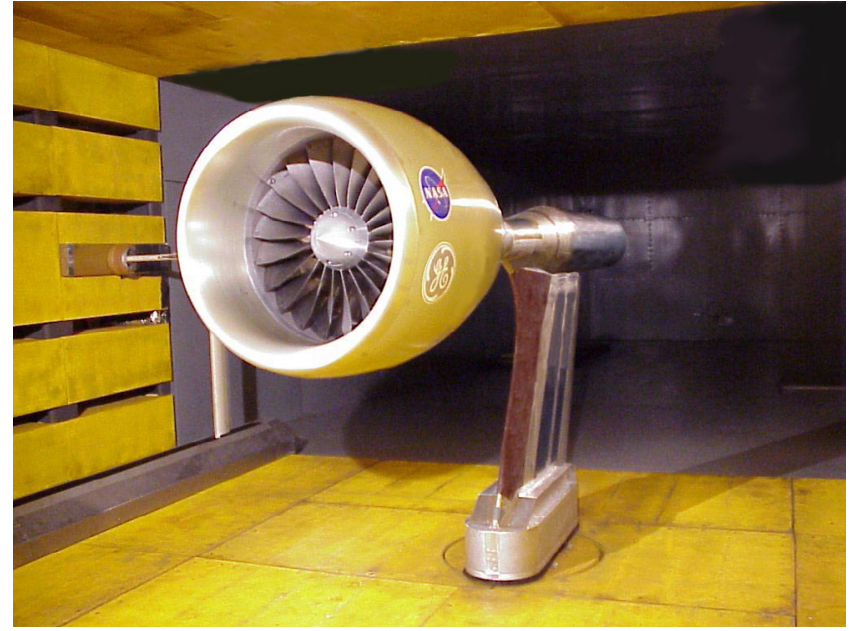

Figure 8.-Photograph of the research fan with the acoustic barrier wall in place.

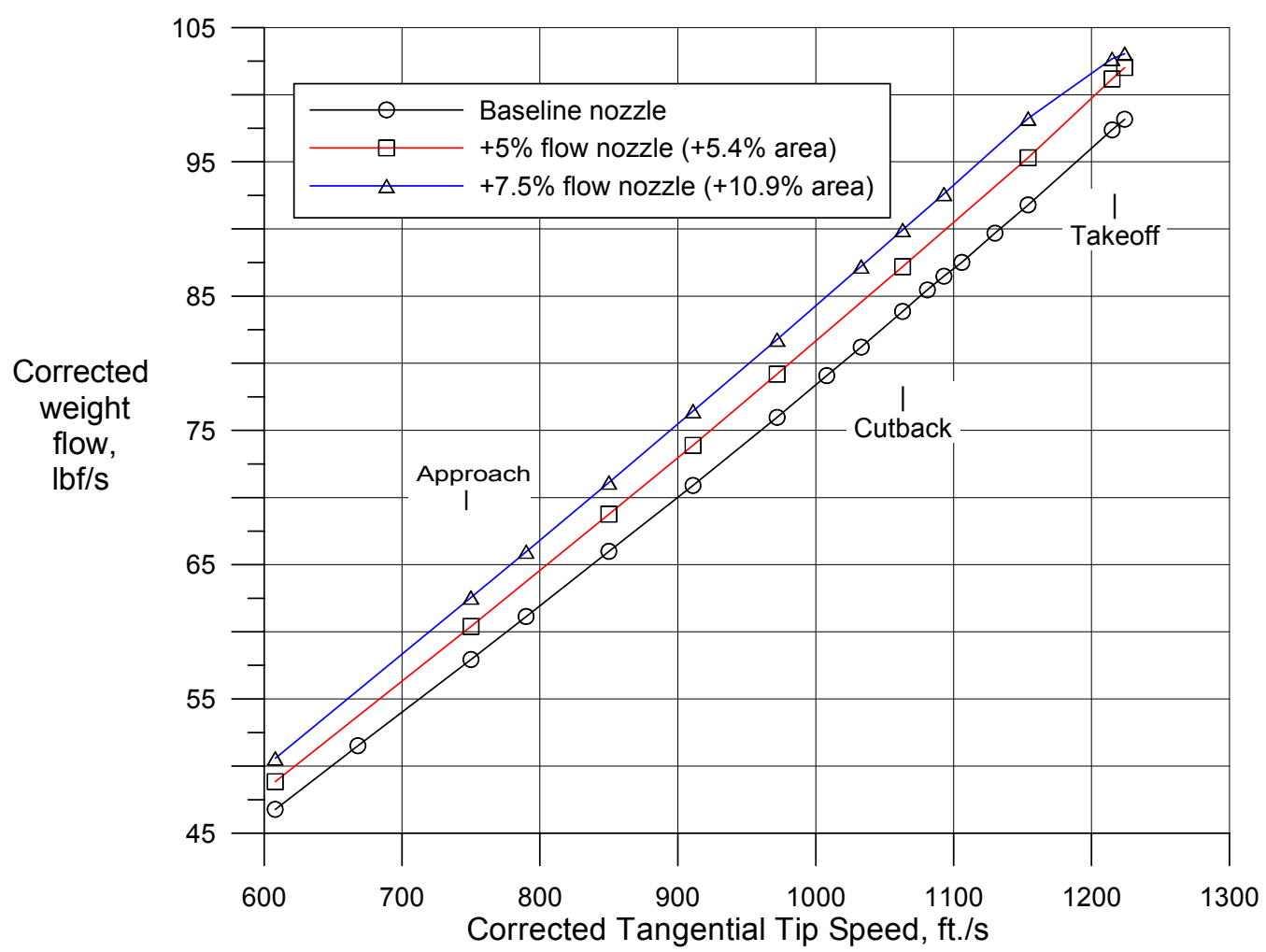

Figure 9.- Corrected weight flow as a function of corrected tangential tip speed for three bypass nozzle flows. 


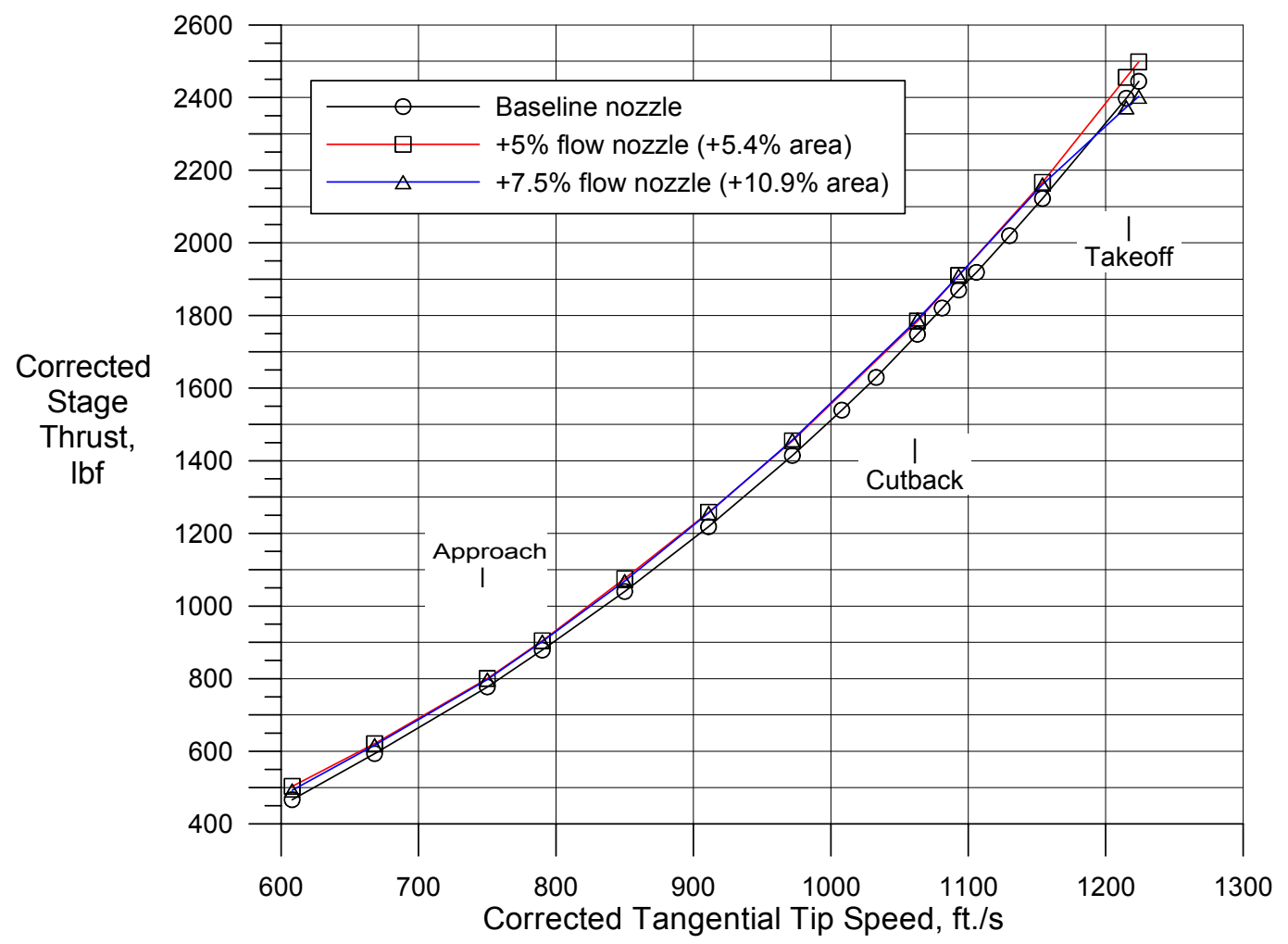

Figure 10.-Corrected stage thrust as a function of corrected tangential tip speed for three bypass nozzle areas.

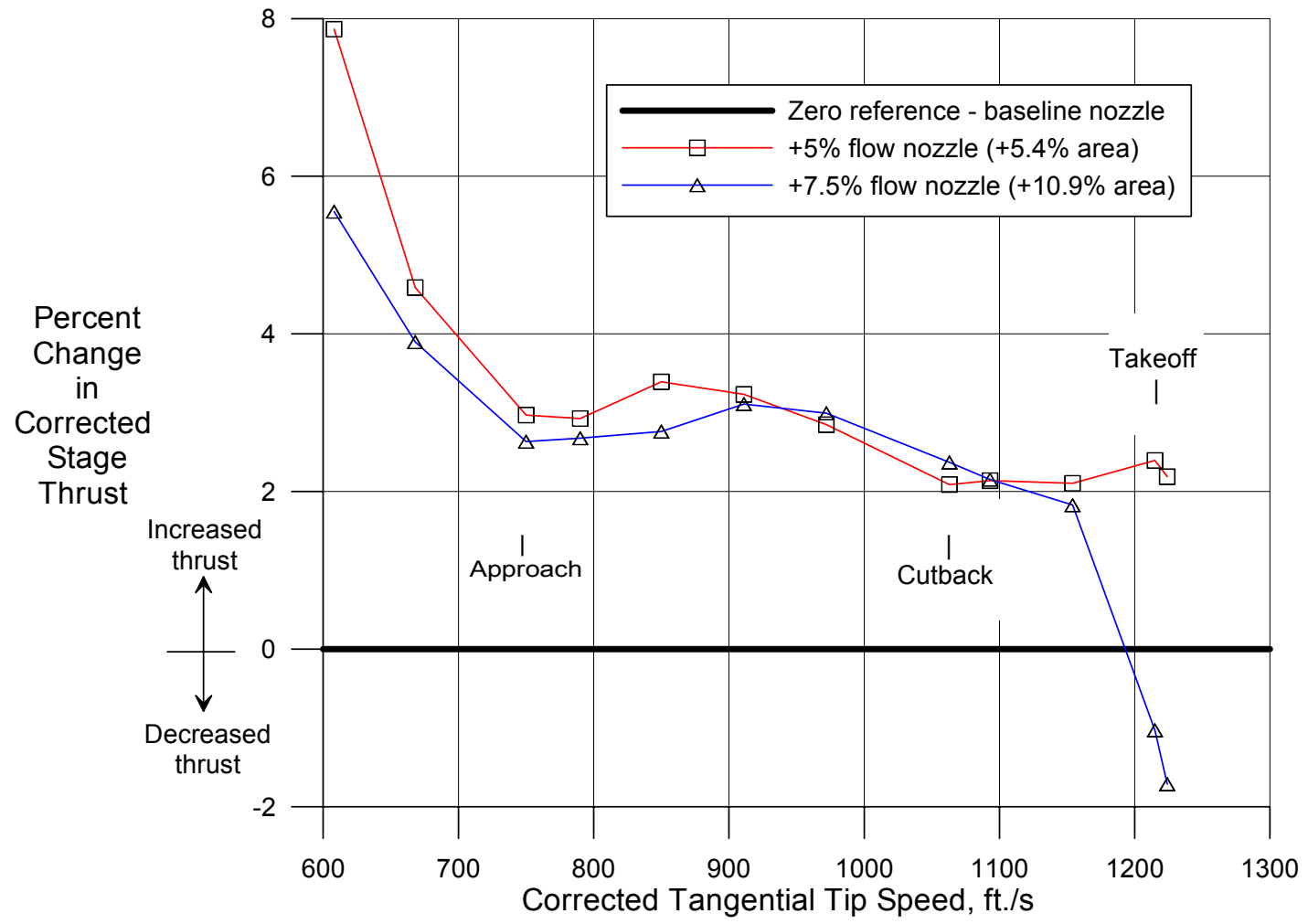

Figure 11.-Percent change in stage thrust as a function of bypass nozzle area. 


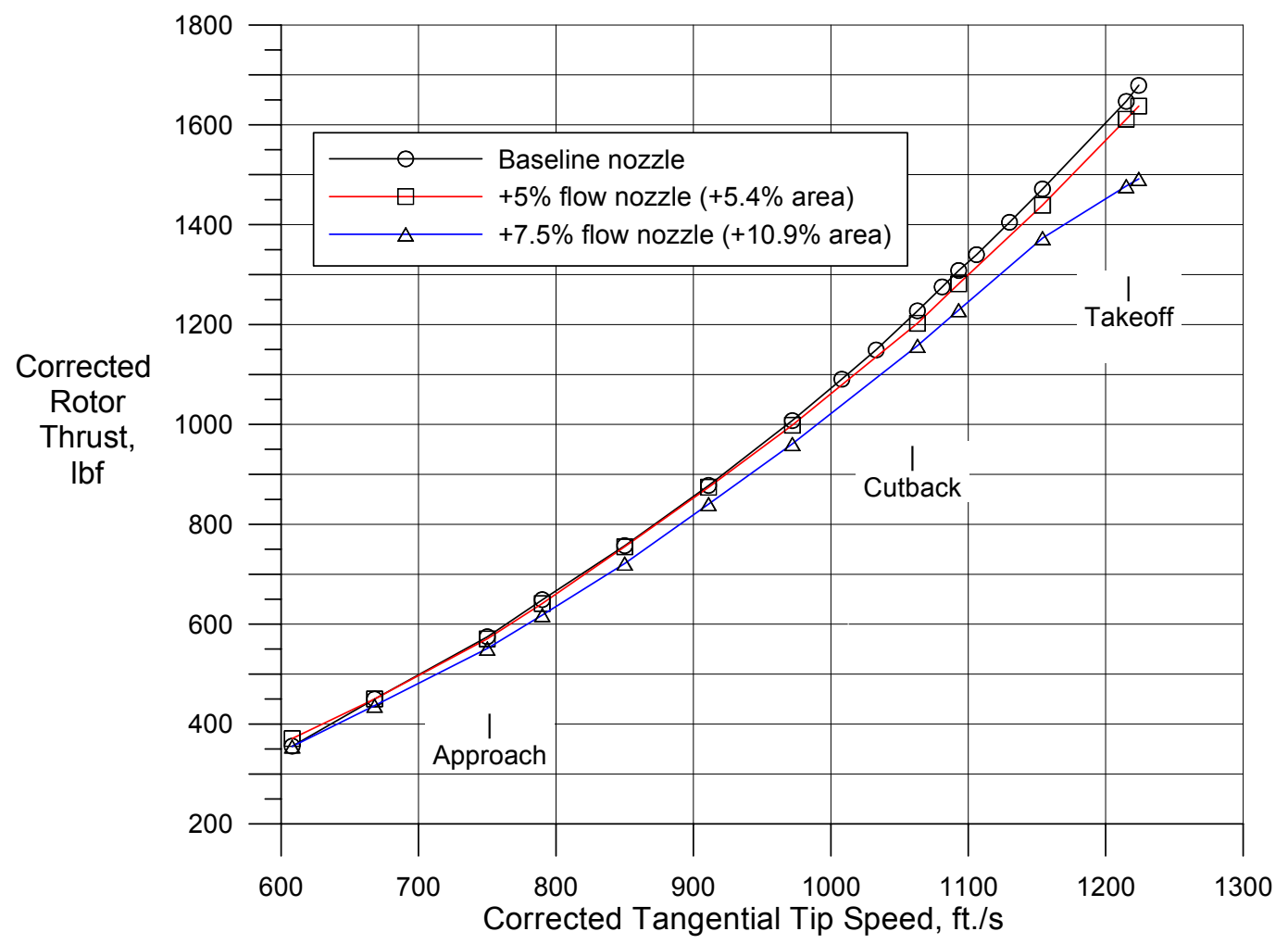

Figure 12.-Corrected rotor thrust as a function of corrected tangential tip speed for three bypass nozzle areas.

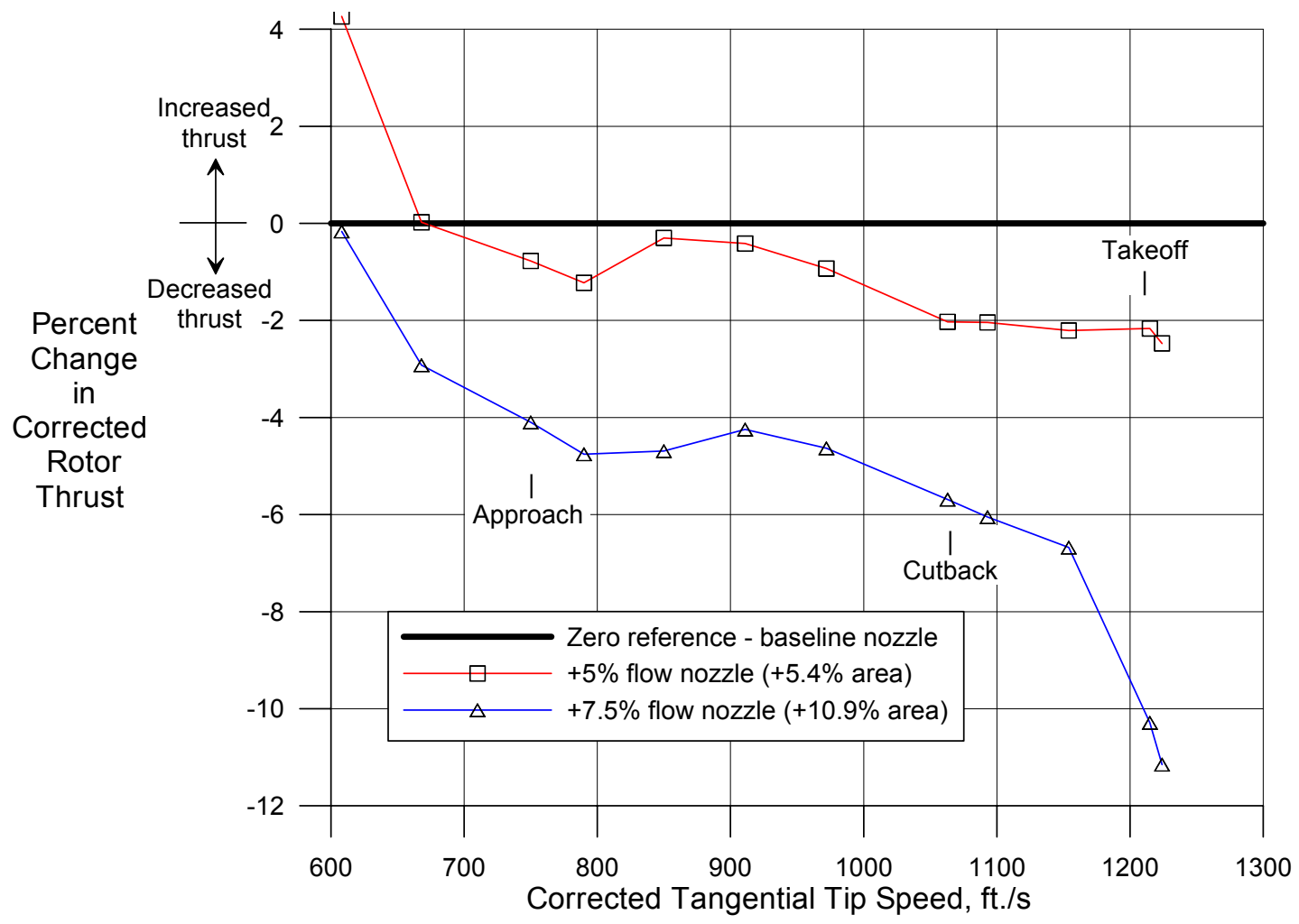

Figure 13.--Percent change in rotor thrust as a function of bypass nozzle area. 


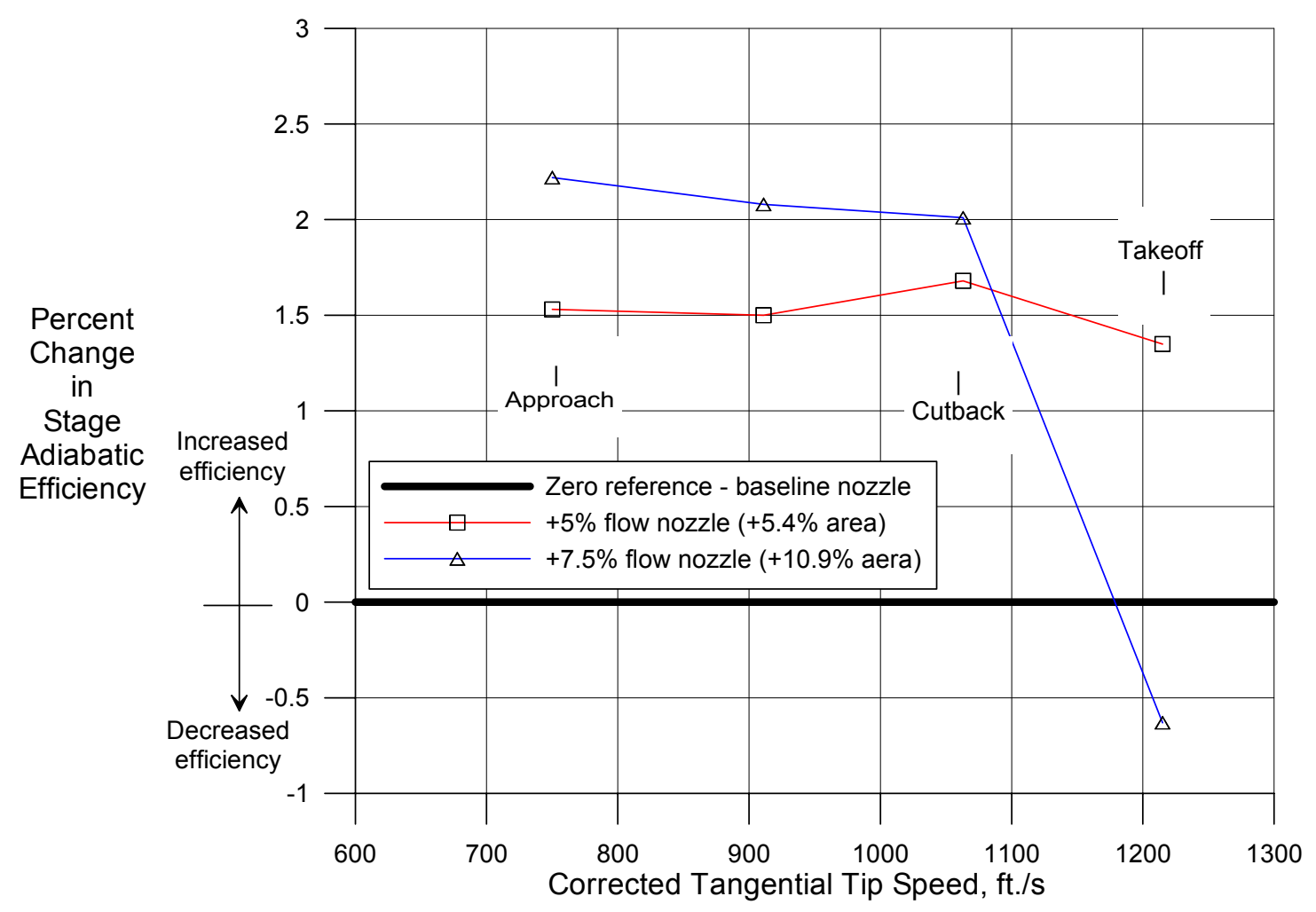

Figure 14.-Percent change in stage adiabatic efficiency as a function of corrected tip speed.

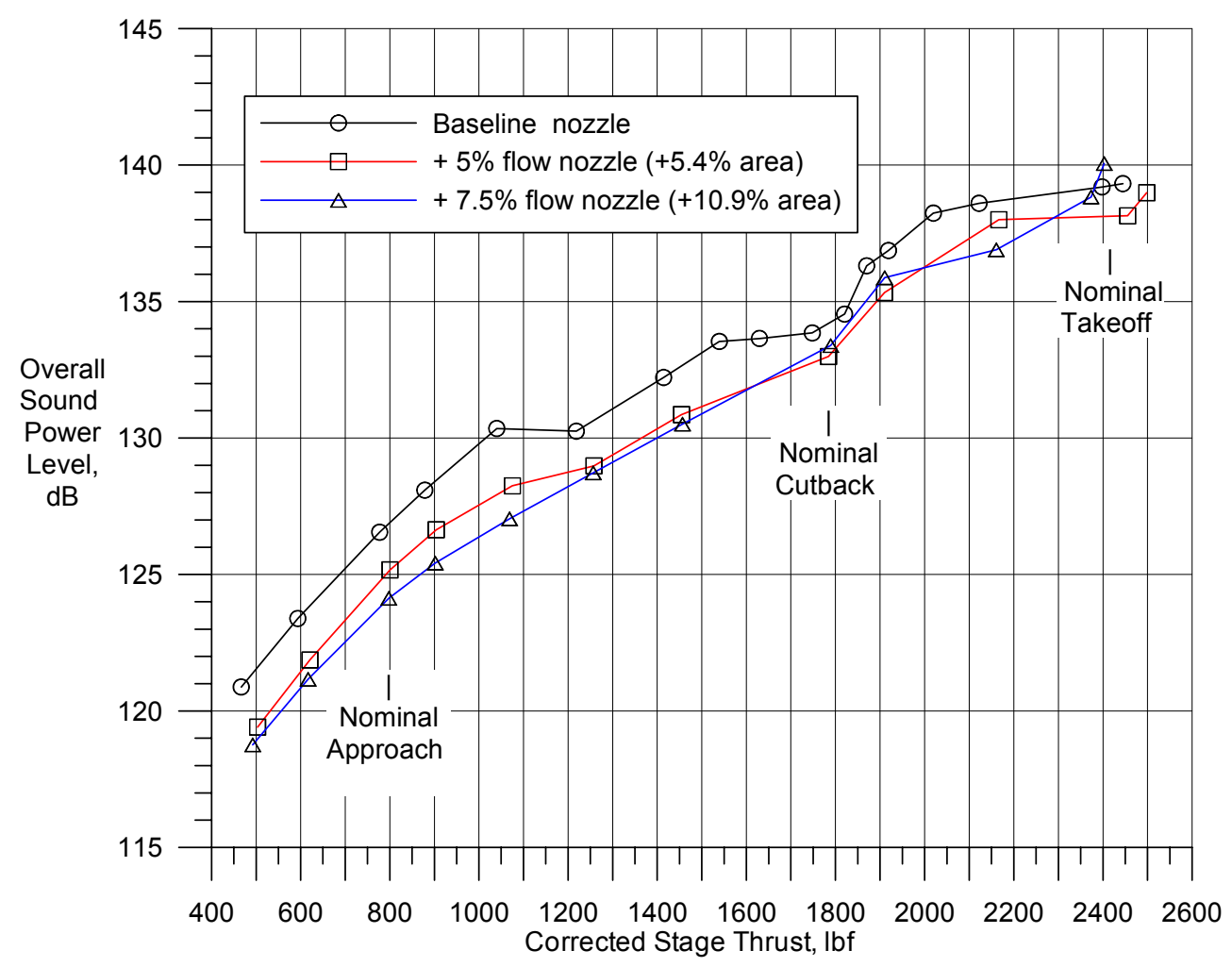

Figure 15.-OAPWL as a function of corrected stage thrust showing potential noise benefits with increased bypass nozzle area. 


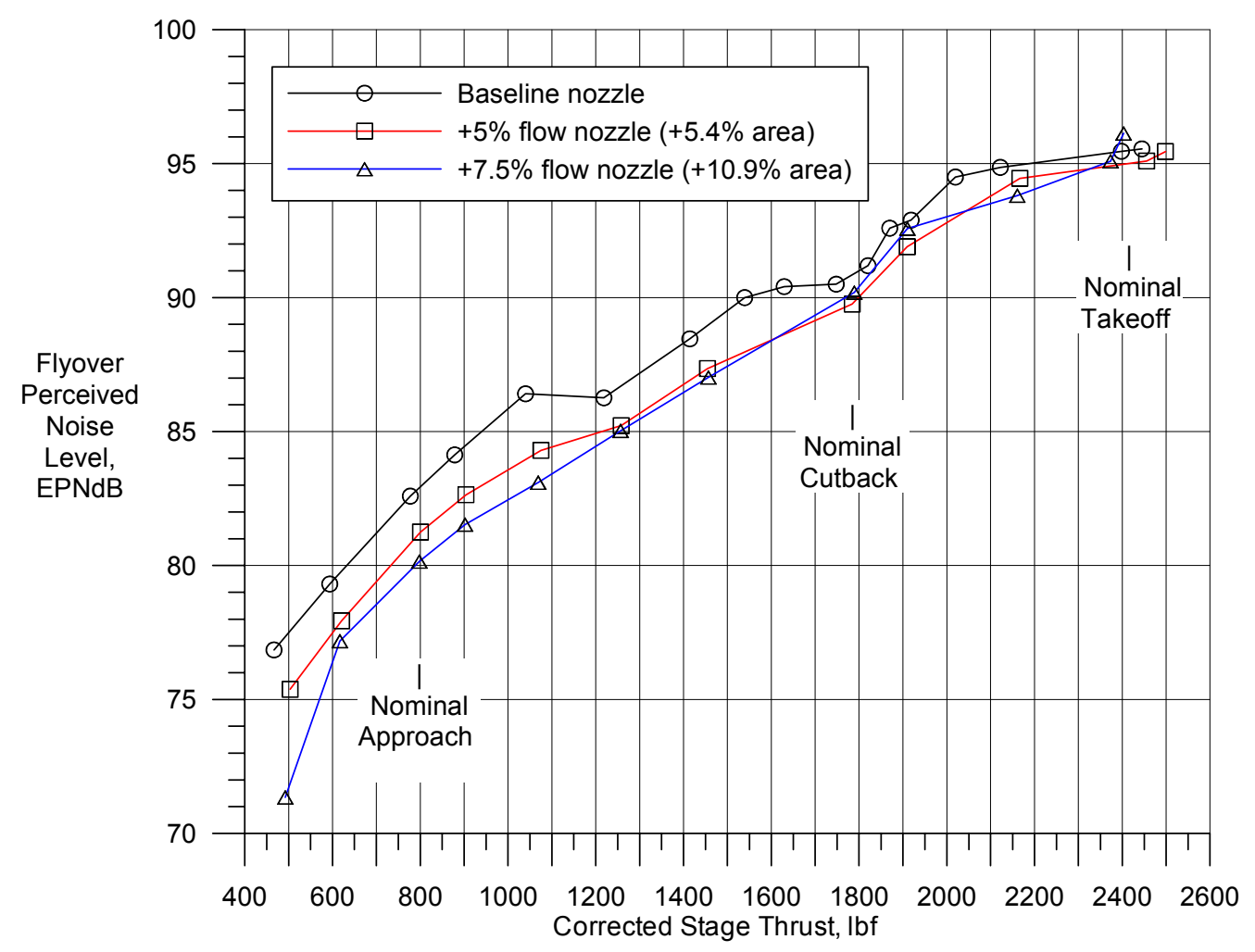

Figure 16.-Perceived noise level as a function of corrected stage thrust.

(1500 ft. flyover and 3.35 scale factor)

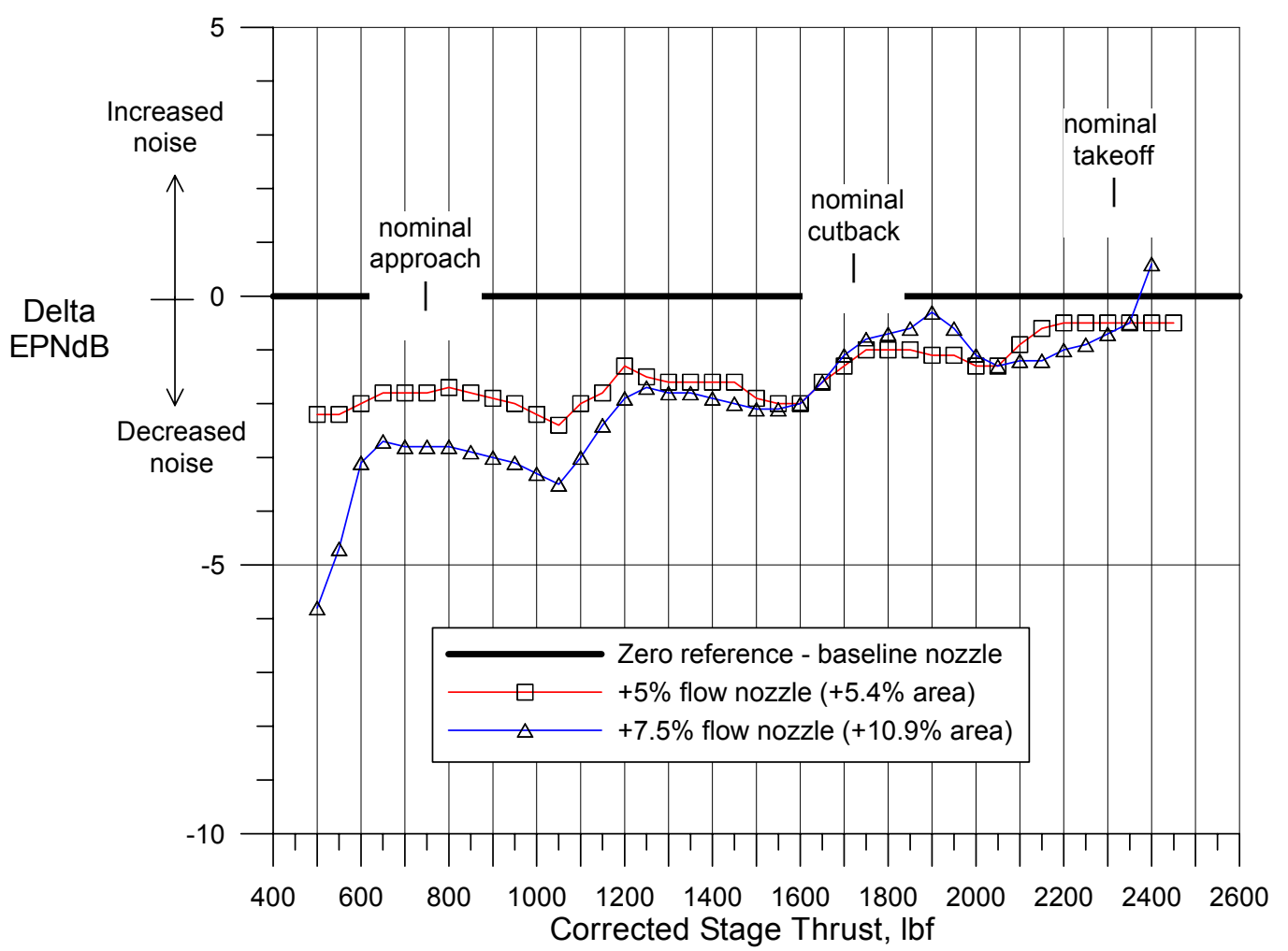

Figure 17.-Effect of nozzle area on EPNL as a function of corrected stage thrust. 


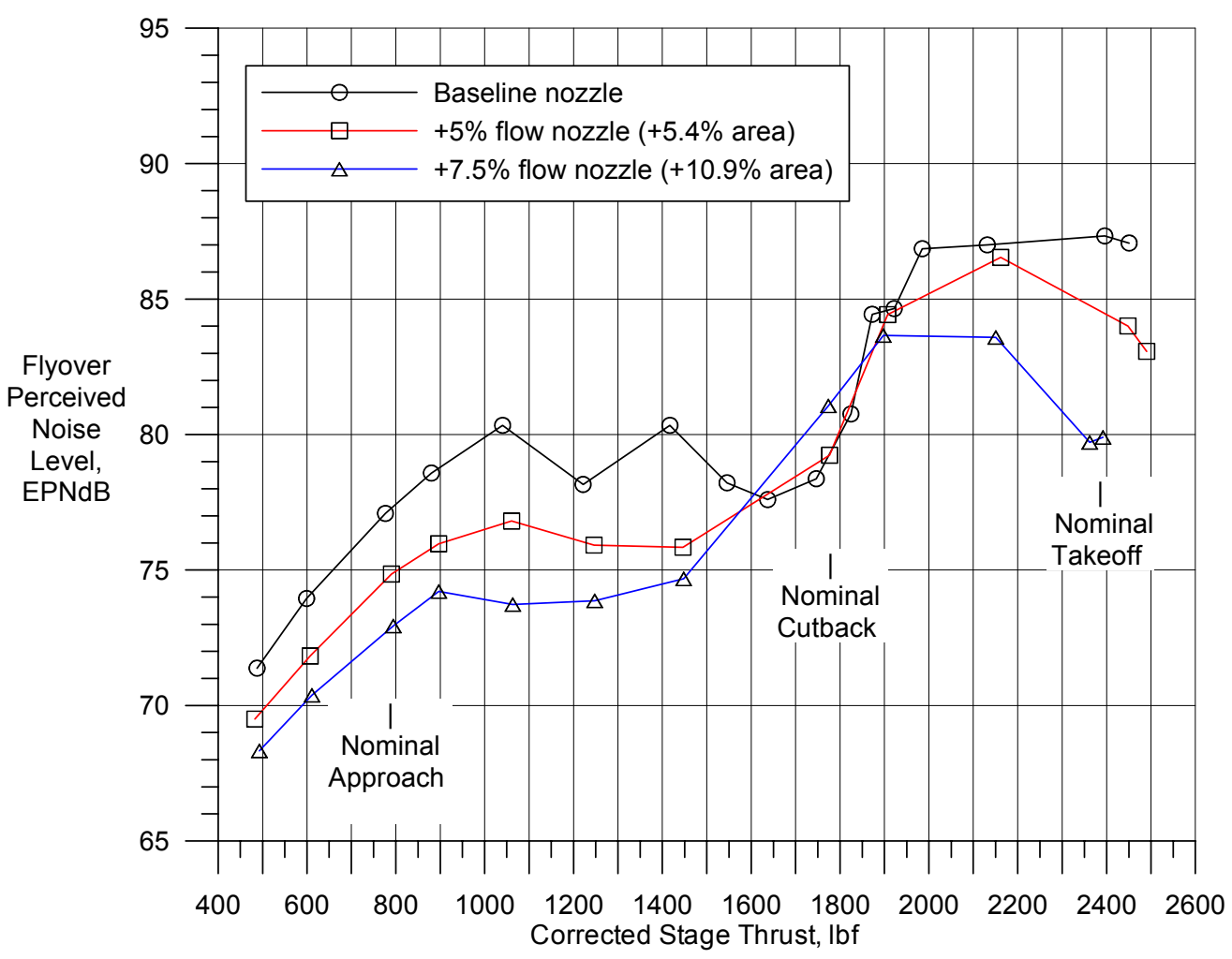

Figure 18.- - Inlet radiating EPNL as a function of corrected stage thrust showing potential noise benefits with increased bypass nozzle area.

(Acoustic barrier wall in place).

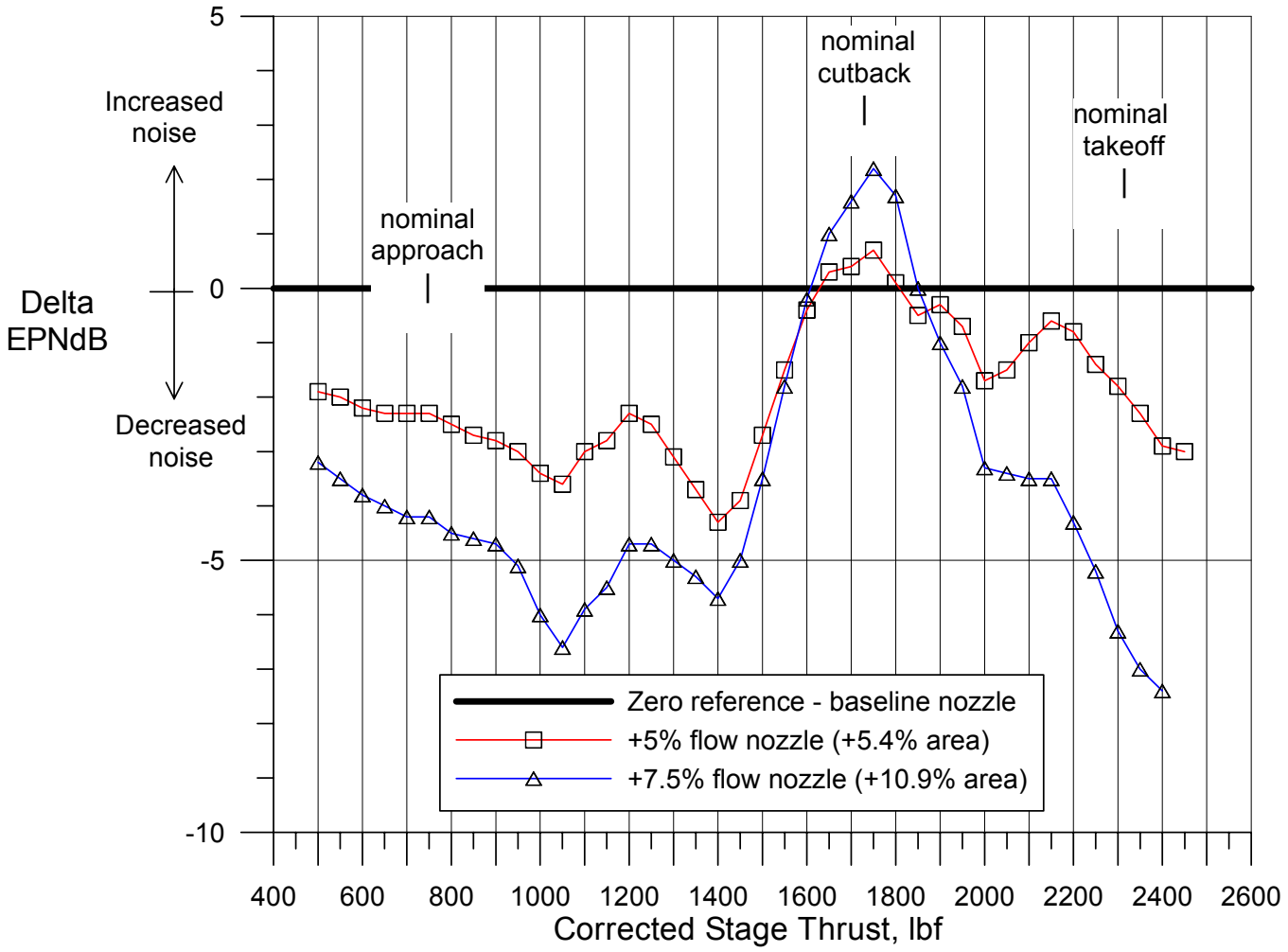

Figure 19.-Effect of nozzle area on inlet radiating OAPWL as a function of corrected stage thrust (acoustic barrier wall in place). 


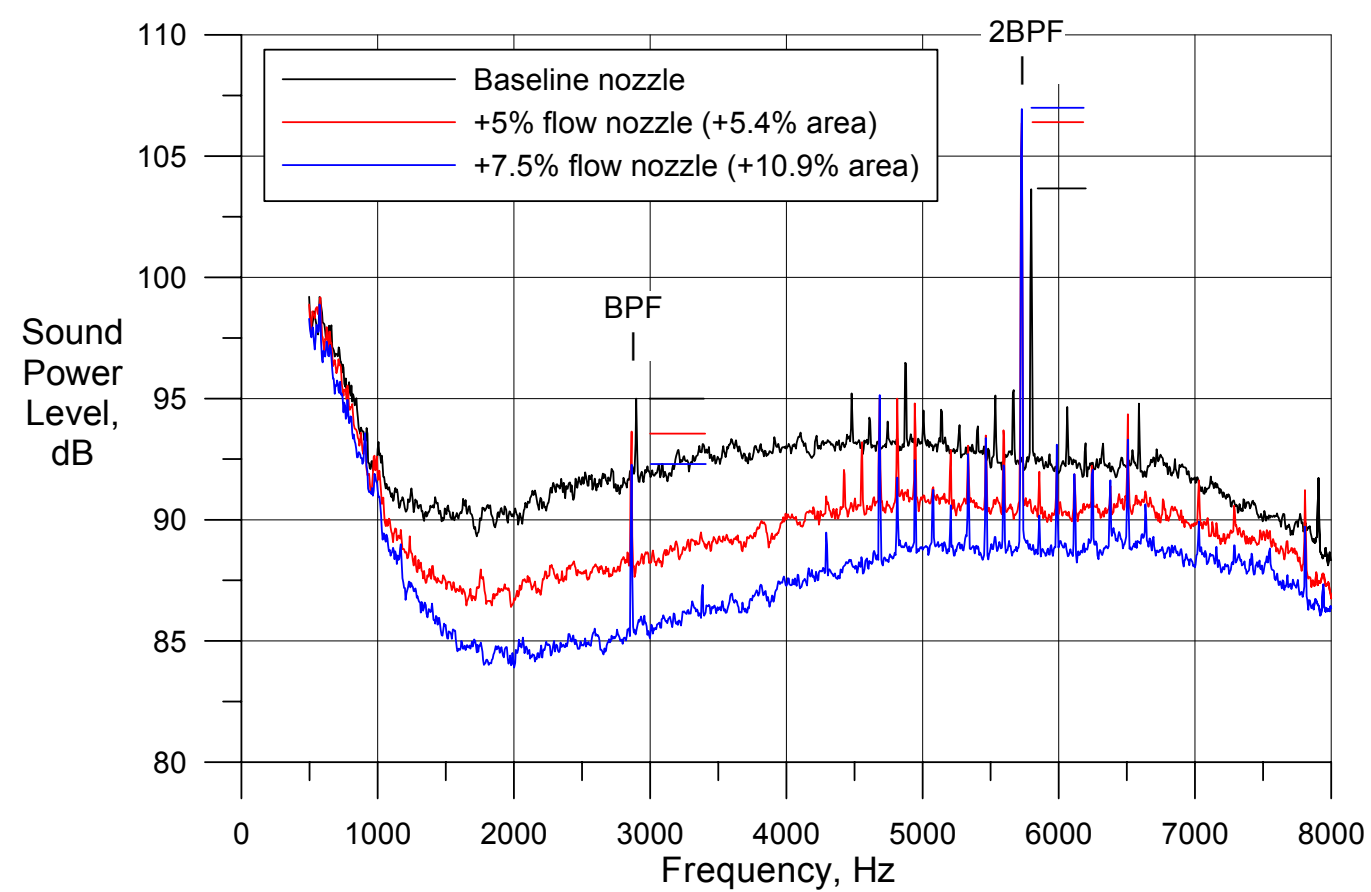

Figure 20.- Sound power level spectra at 61.7 percent fan design speed (designated approach speed, $5.9 \mathrm{~Hz}$ bandwidth, no barrier wall).

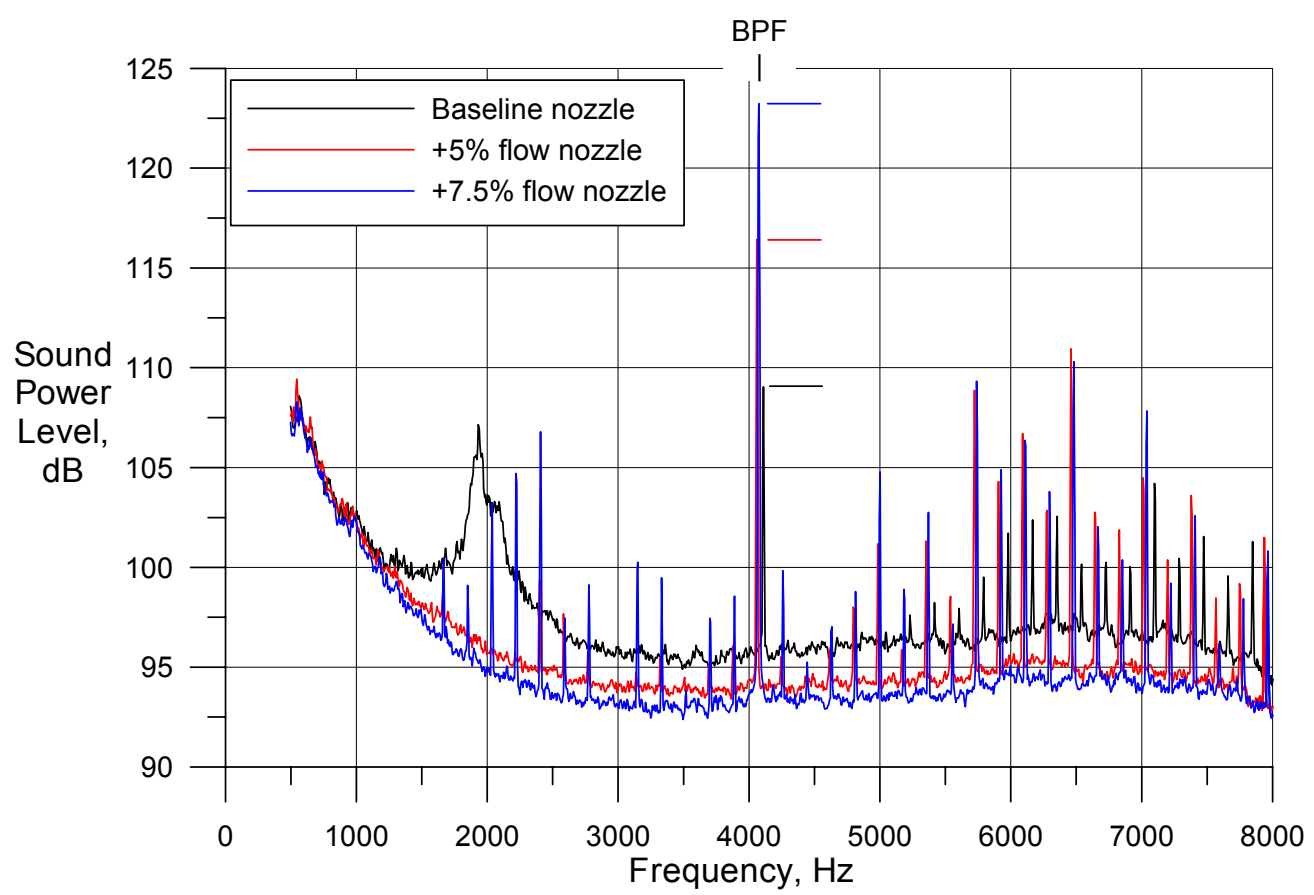

Figure 21.-Sound power level spectra at 87.5 percent fan design speed (designated cutback speed, $5.9 \mathrm{~Hz}$ bandwidth, no barrier wall). 


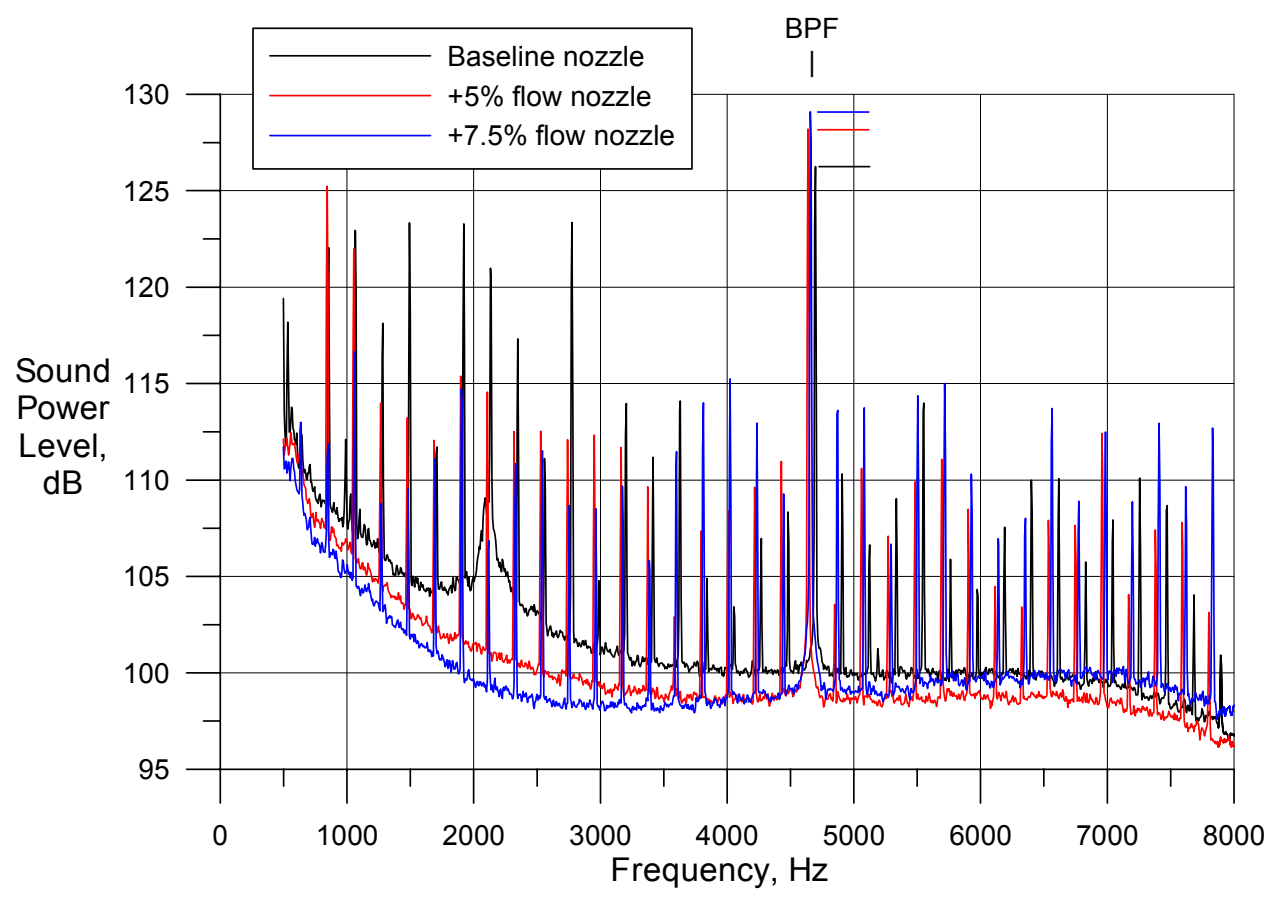

Figure 22.- Sound power level spectra at 100 percent fan design speed (designated takeoff speed, $5.9 \mathrm{~Hz}$ bandwidth no barrier wall). 


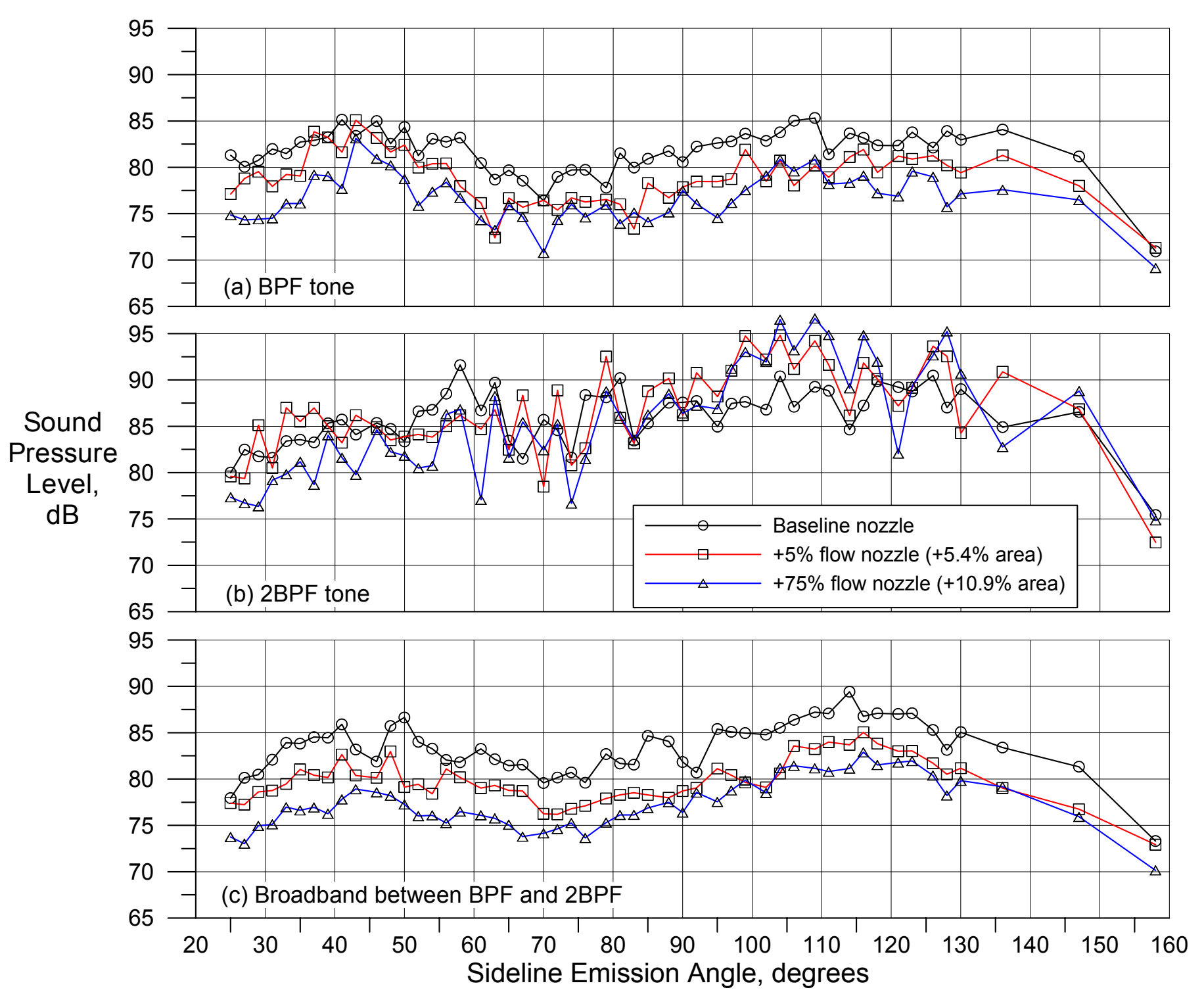

Figure 23.- Sound pressure level directivities at 61.7 percent fan design speed (89 inch sideline, no barrier wall, $59 \mathrm{~Hz}$ bandwidth). 


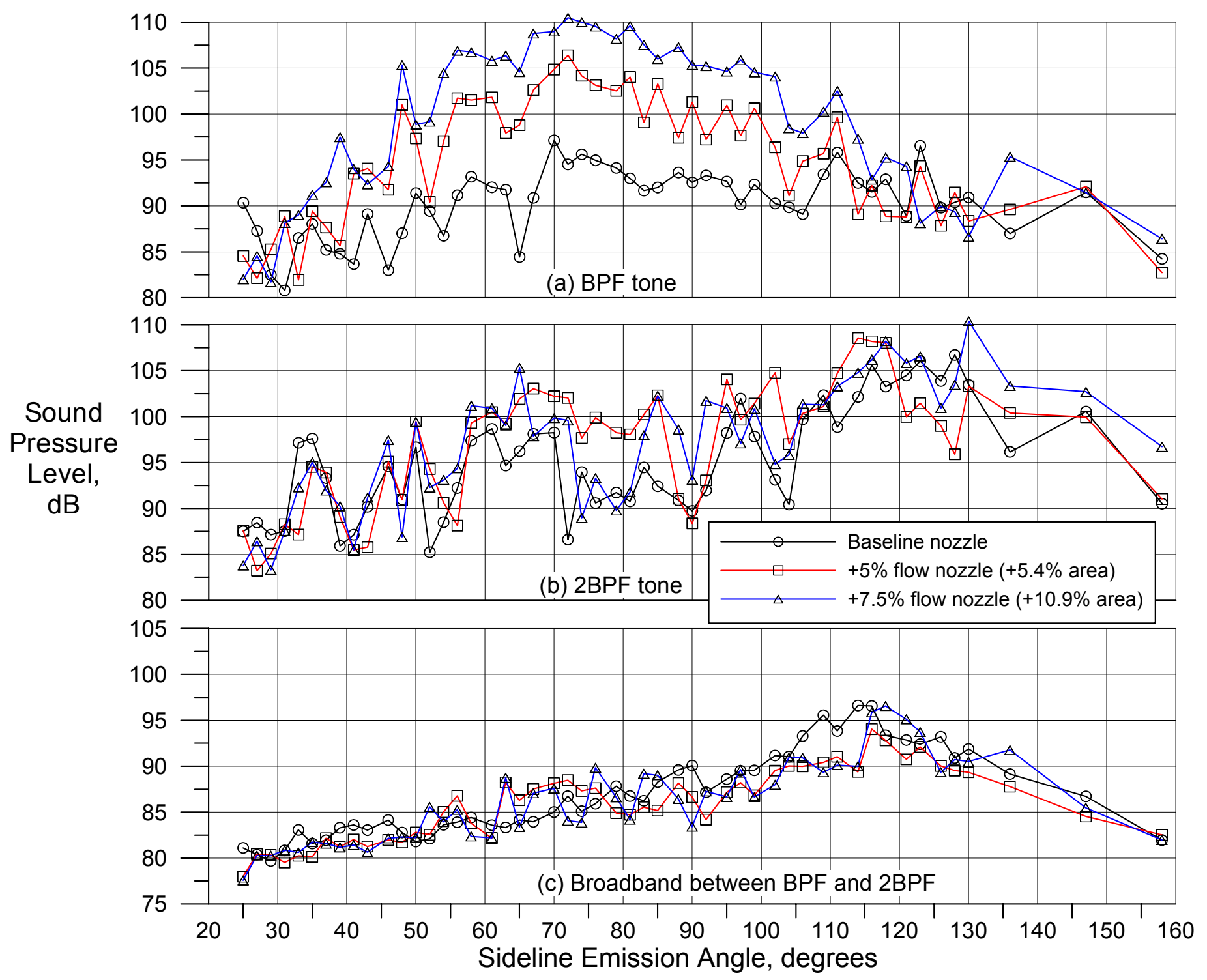

Figure 24.- Sound pressure level directivities at 87.5 percent fan design speed (89 inch sideline, no barrier wall, $59 \mathrm{~Hz}$ bandwidth). 


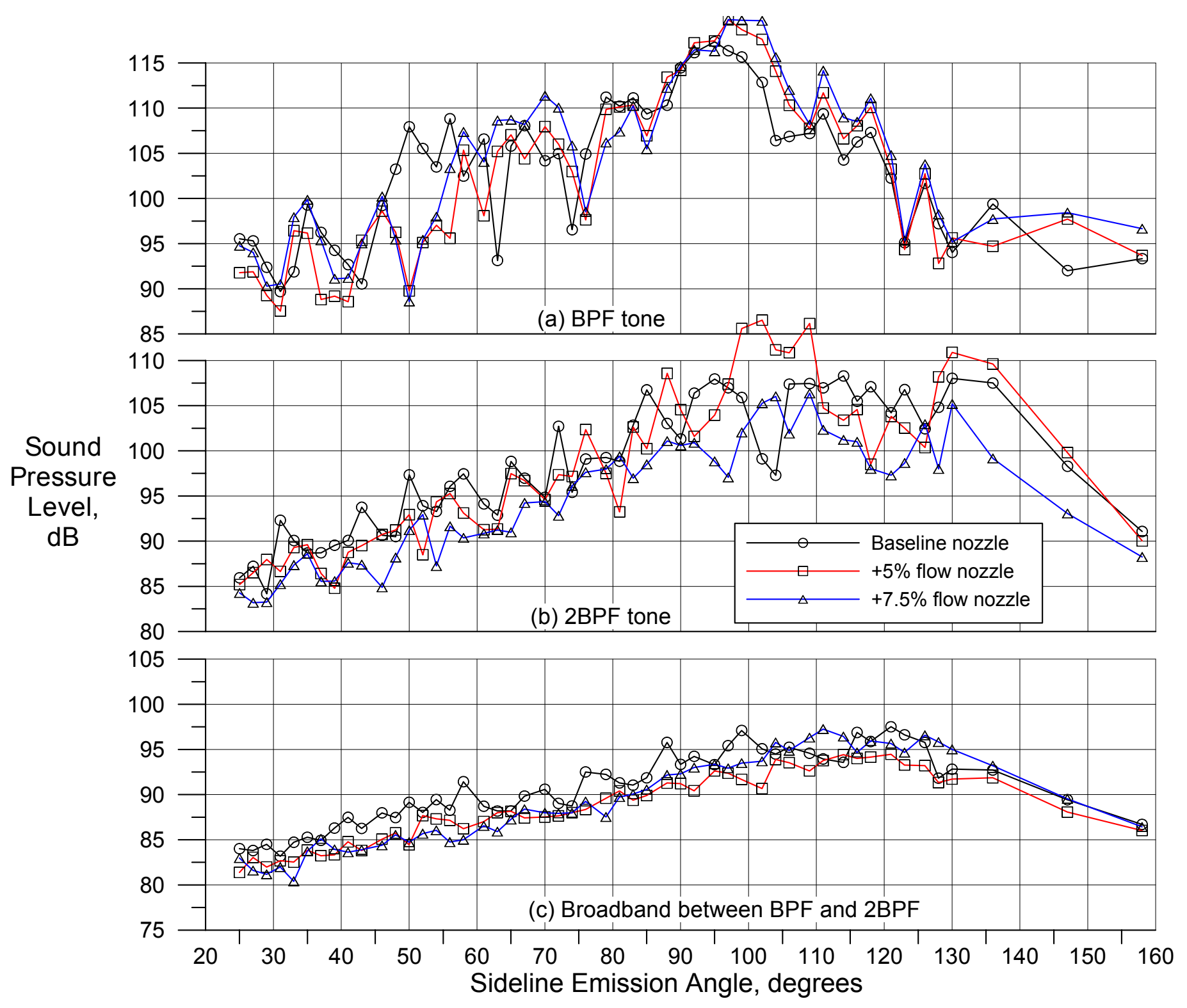

Figure 25.- Sound pressure level directivities at 100 percent fan design speed (89 inch sideline, no barrier wall, $59 \mathrm{~Hz}$ bandwidth). 


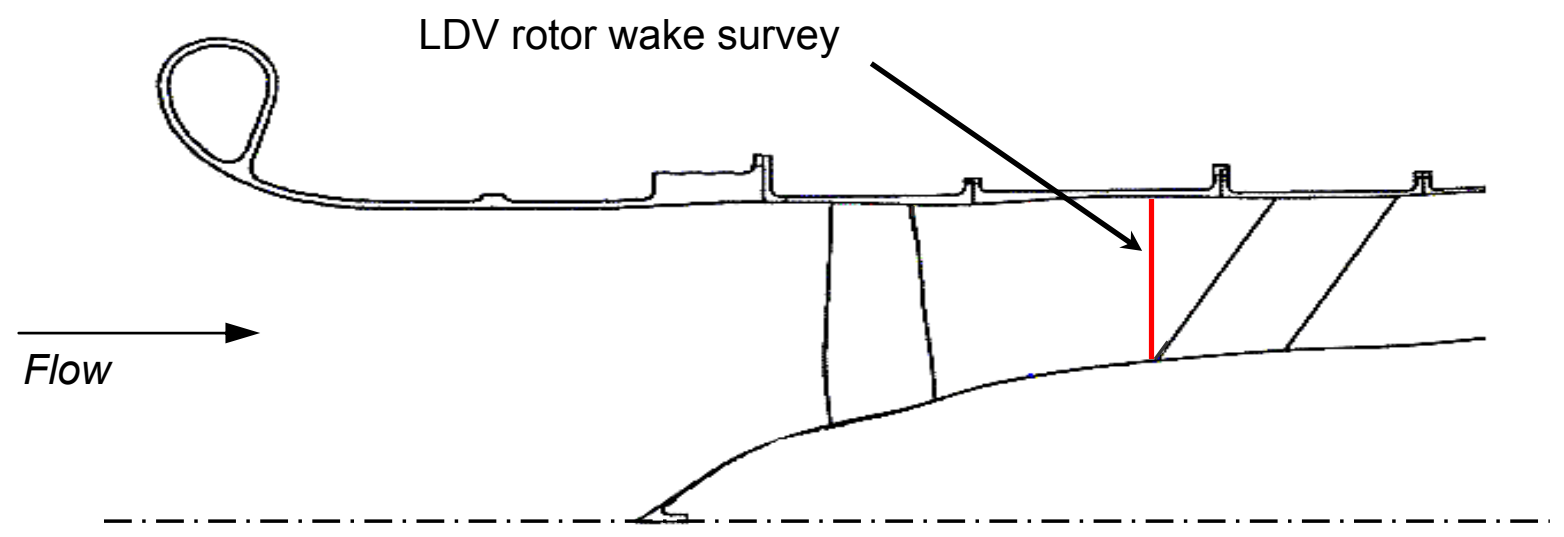

Figure 26.--Location of LDV rotor wake survey.

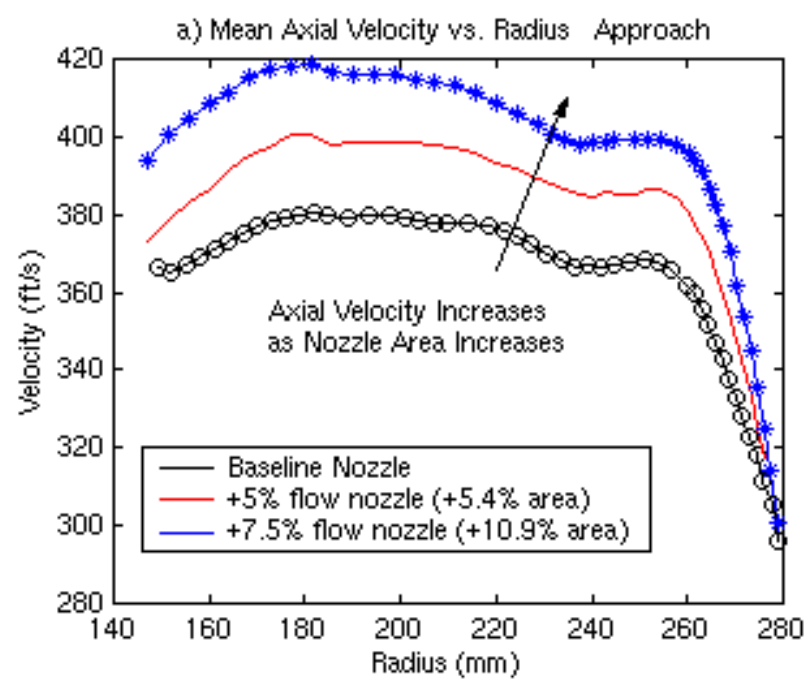

b) Mean Tangential Velocity vs. Radius Approach

c) Swirl Angle vs. Radius Approach

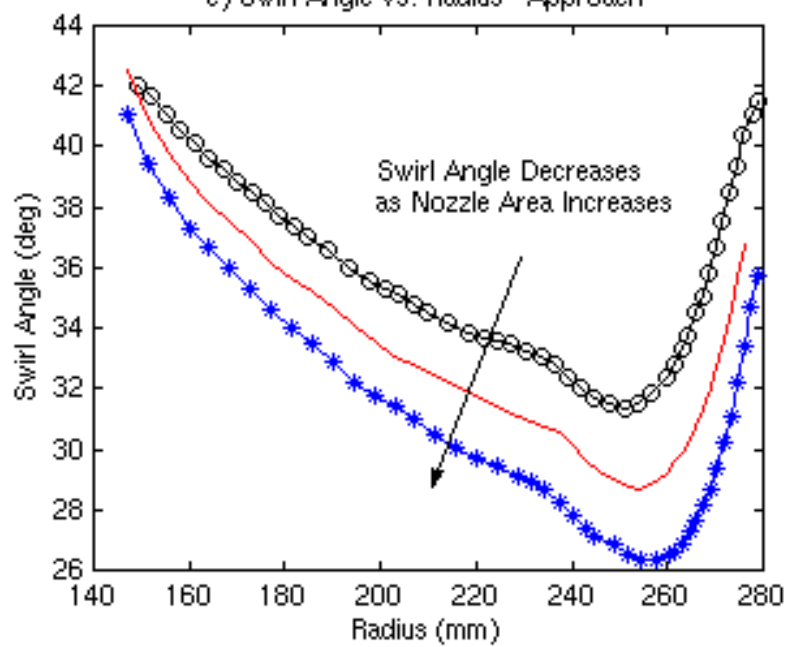

d) Total Turbulent Velocity vs. Radius Approach

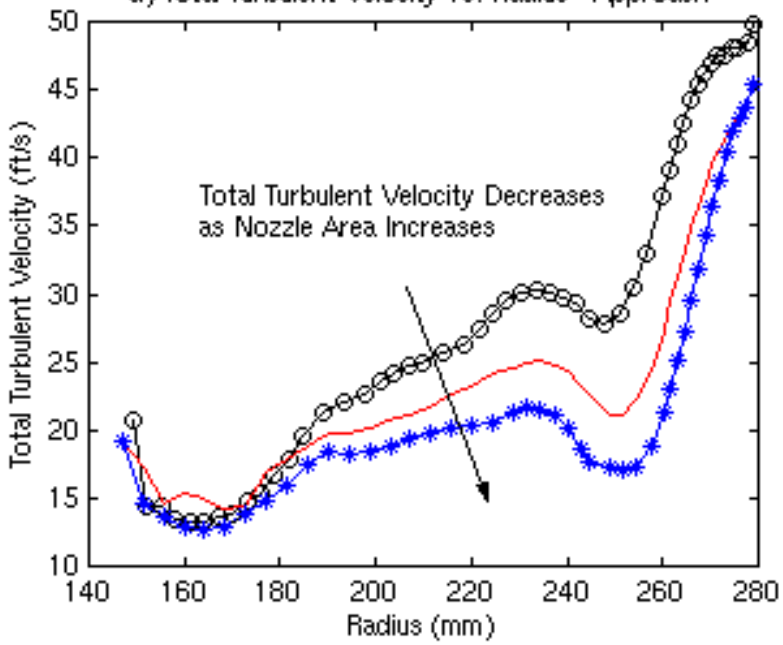

Figure 27.- Change in rotor wake flow with nozzle area as measure at the fan approach condition (61.7 percent speed). 
a) Mean Axial Velocity vs. Radius cutback

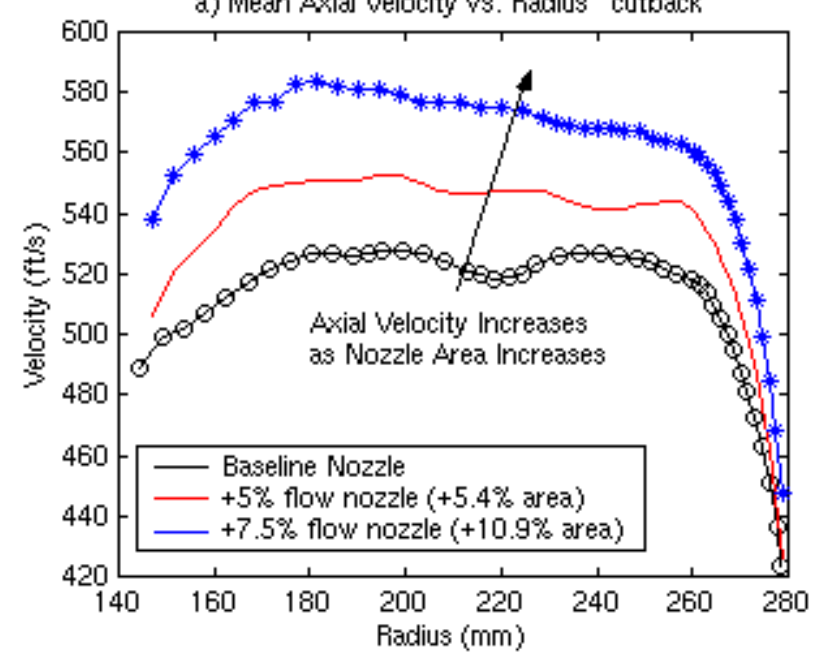

c) Swirl Angle vs. Radius Cutback

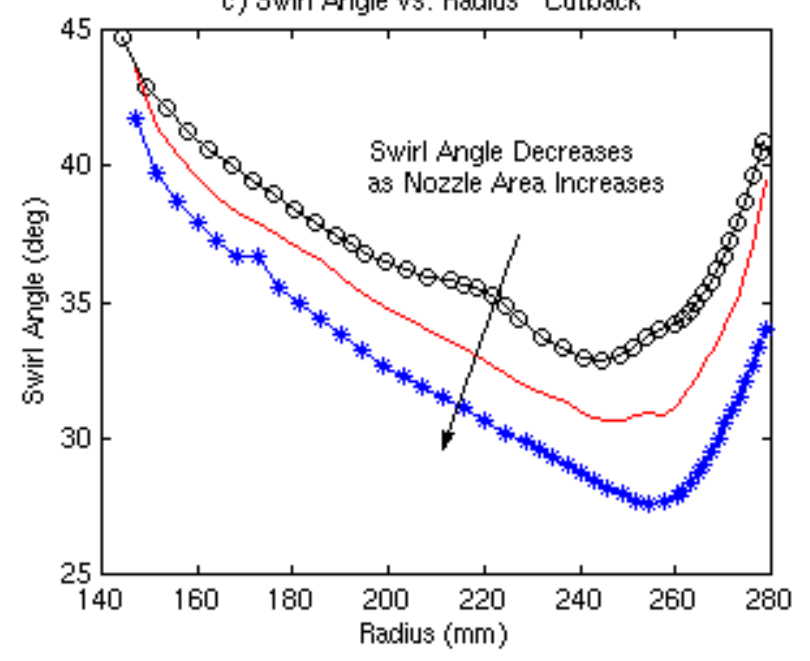

b) Mean Tangential Velocity vs. Radius Cutback

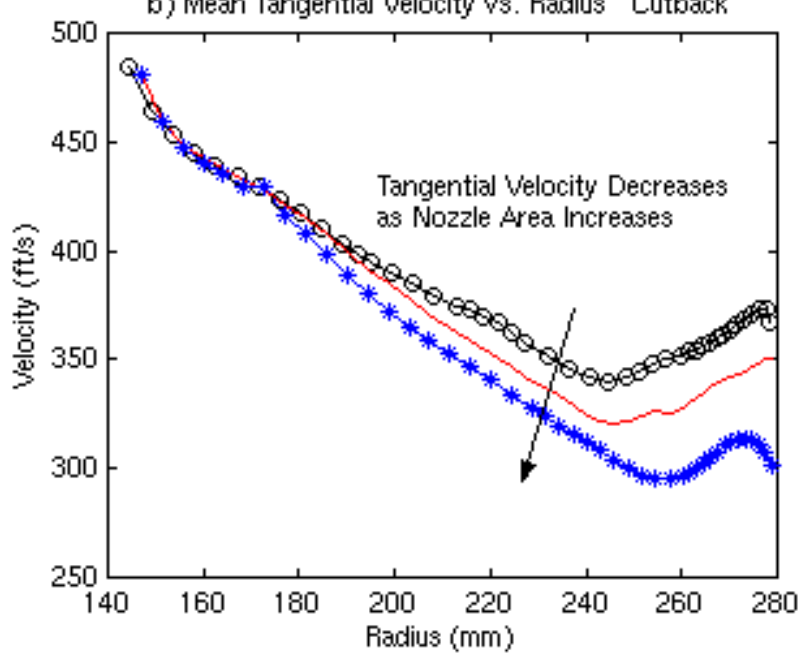

d) Total Turbulent Velocity vs. Radius Cutback

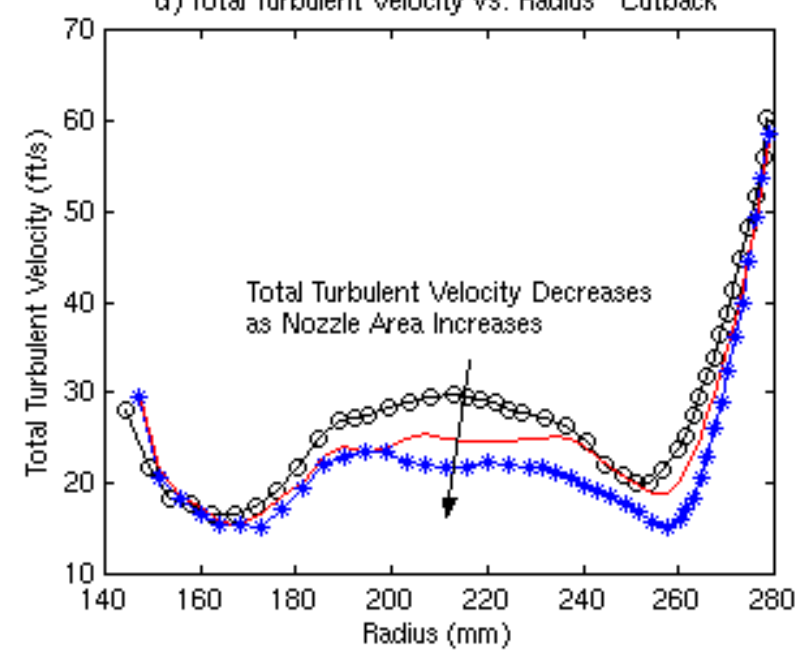

Figure 28.-Change in rotor wake flow with nozzle area as measured at the fan cut-back condition ( 87.5 percent speed). 

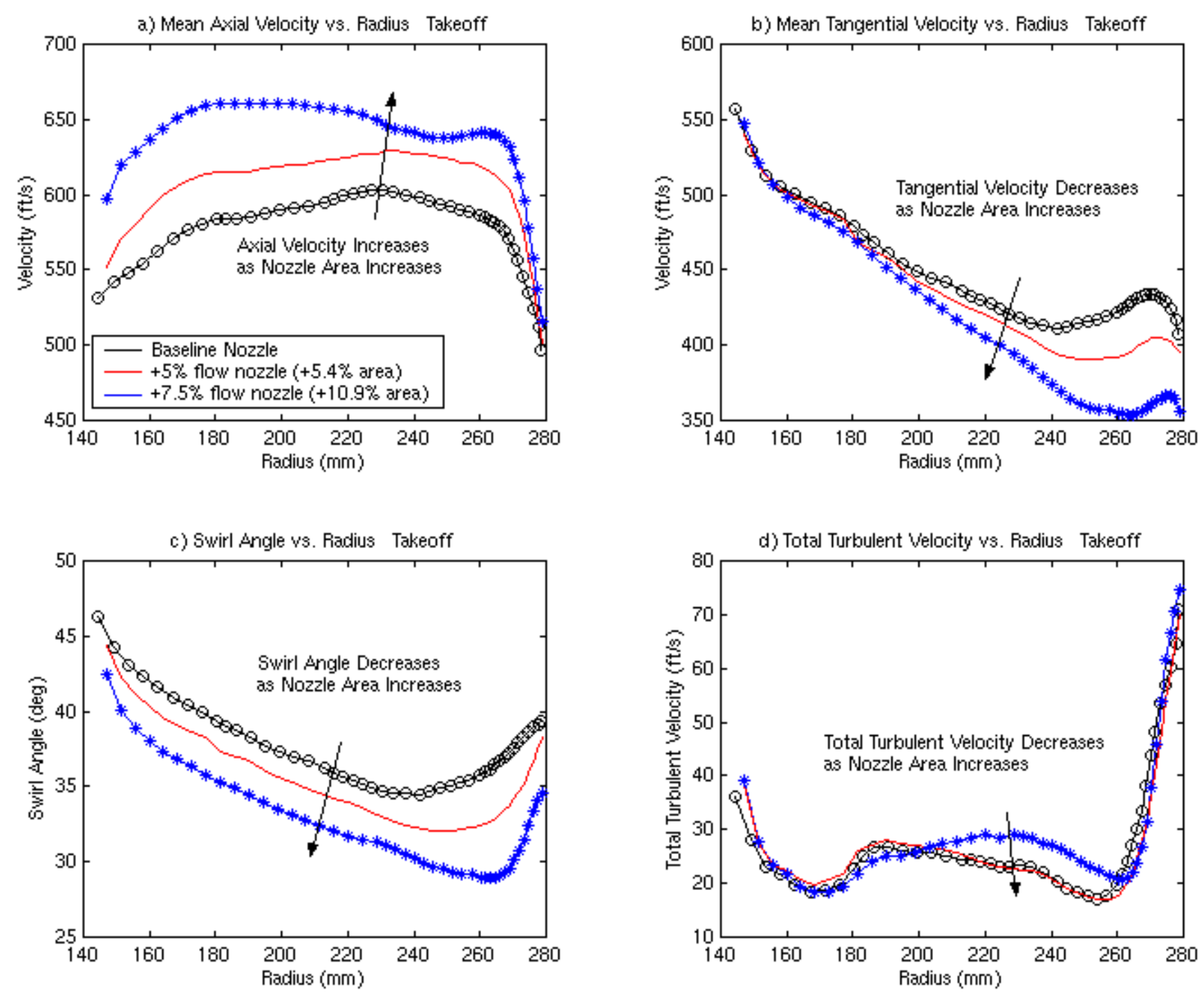

Figure 29.-Change in rotor wake flow with nozzle area as measured at the fan take-off condition (100 percent speed). 

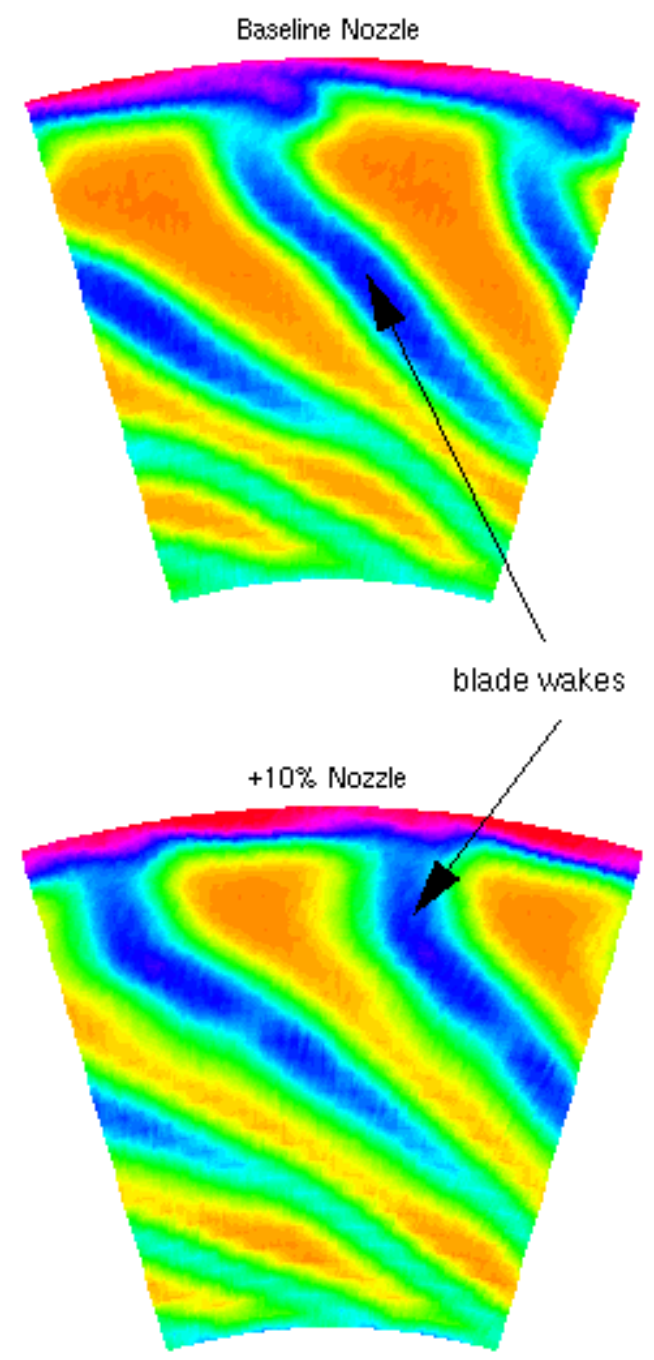

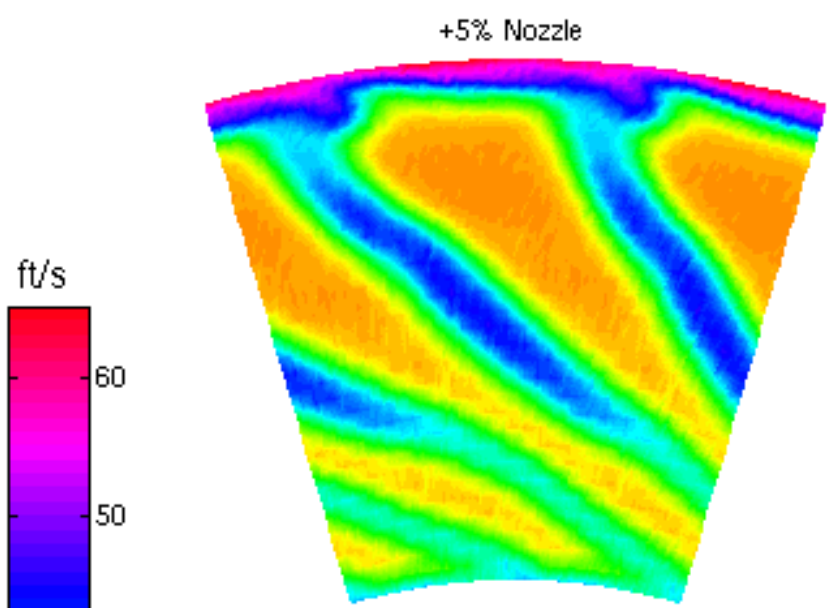

40

Figure GP4. Aft-looking forward view of total turbulent velocity contours measured in the rotor wake at $100 \%$ speed for each of the three nozzles.

Figure 30.-Aft-looking forward view of total turbulent velocity contours measured in the rotor wake at 100 percent speed for each of the three nozzles. 
Public reporting burden for this collection of information is estimated to average 1 hour per response, including the time for reviewing instructions, searching existing data sources, gathering and maintaining the data needed, and completing and reviewing the collection of information. Send comments regarding this burden estimate or any other aspect of this collection of information, including suggestions for reducing this burden, to Washington Headquarters Services, Directorate for Information Operations and Reports, 1215 Jefferson Davis Highway, Suite 1204, Arlington, VA 22202-4302, and to the Office of Management and Budget, Paperwork Reduction Project (0704-0188), Washington, DC 20503.

\begin{tabular}{|l|l|l} 
1. AGENCY USE ONLY (Leave blank) & $\begin{array}{c}\text { 2. REPORT DATE } \\
\text { July } 2005\end{array}$ & $\begin{array}{c}\text { 3. REPORT TYPE AND DATES COVERED } \\
\text { Technical Memorandum }\end{array}$
\end{tabular}

4. TITLE AND SUBTITLE 5. FUNDING NUMBERS

Aeroacoustic Analysis of Fan Noise Reduction With Increased Bypass Nozzle Area

6. AUTHOR(S)

Richard P. Woodward, Christopher E. Hughes, and Gary G. Podboy

WBS-22-781-30-58

7. PERFORMING ORGANIZATION NAME(S) AND ADDRESS(ES)

National Aeronautics and Space Administration

John H. Glenn Research Center at Lewis Field

Cleveland, Ohio 44135-3191

8. PERFORMING ORGANIZATION REPORT NUMBER

E-15184

9. SPONSORING/MONITORING AGENCY NAME(S) AND ADDRESS(ES)

National Aeronautics and Space Administration

Washington, DC 20546-0001

10. SPONSORING/MONITORING AGENCY REPORT NUMBER

NASA TM-2005-213825

AIAA-2005-3075

\section{SUPPLEMENTARY NOTES}

Prepared for the 11th Aeroacoustics Conference cosponsored by the American Institute of Aeronautics and Astronautics and the Confederation of European Aerospace Societies, Monterey, California, May 23-25, 2005. Responsible person, Richard P. Woodward, organization code RTA, 216-433-3923.

12a. DISTRIBUTION/AVAILABILITY STATEMENT 12b. DISTRIBUTION CODE

Unclassified - Unlimited

Subject Category: 07

Available electronically at http://gltrs.grc.nasa.gov

This publication is available from the NASA Center for AeroSpace Information, 301-621-0390.

13. ABSTRACT (Maximum 200 words)

An advanced model turbofan was tested in the NASA Glenn 9- by 15-Foot Low Speed Wind Tunnel (9x15 LSWT) to explore far field acoustic effects of increased bypass nozzle area. This fan stage test was part of the NASA Glenn Fan Broadband Source Diagnostic Test, second entry (SDT2) which acquired aeroacoustic results over a range of test conditions. The baseline nozzle was sized to produce maximum stage performance at cruise condition. However, the wind tunnel testing is conducted near sea level condition. Therefore, in order to simulate and obtain performance at other operating conditions, two additional nozzles were designed and tested - one with +5 percent increase in weight flow ( +5.4 percent increase in nozzle area compared with the baseline nozzle), sized to simulate the performance at the stage design point (takeoff) condition, and the other with a +7.5 percent increase in weight flow $(+10.9$ percent increase in nozzle area) sized for maximum weight flow with a fixed nozzle at sea level condition. Measured acoustic benefits with increased nozzle area were very encouraging, showing overall sound power level (OAPWL) reductions of 2 or more $\mathrm{dB}$ while the stage thrust actually increased by 2 to 3 percent except for the most open nozzle at takeoff rotor speed where stage performance decreased. Effective perceived noise levels for a $1500 \mathrm{ft}$ engine flyover and 3.35 scale factor showed a similar noise reduction of 2 or more EPNdB. Noise reductions, principally in the level of broadband noise, were observed everywhere in the far field. Laser Doppler Velocimetry measurements taken downstream of the rotor showed that the total turbulent velocity decreased with increasing nozzle flow, which may explain the reduced rotor broadband noise levels.

14. SUBJECT TERMS

Aircraft engine performance; Engine noise; Noise reduction

\begin{tabular}{|c|c|c|c|}
\hline $\begin{array}{c}\text { 17. SECURITY CLASSIFICATION } \\
\text { OF REPORT } \\
\text { Unclassified }\end{array}$ & $\begin{array}{c}\text { 18. SECURITY CLASSIFICATION } \\
\text { OF THIS PAGE } \\
\text { Unclassified }\end{array}$ & $\begin{array}{c}\text { 19. SECURITY CLASSIFICATION } \\
\text { OF ABSTRACT } \\
\text { Unclassified }\end{array}$ \\
\hline
\end{tabular}

NSN 7540-01-280-5500

Standard Form 298 (Rev. 2-89)

Prescribed by ANSI Std. Z39-18 298-102 

